\title{
Short-Term Cooperative Operational Scheme of Distribution System with High Hosting Capacity of Renewable-Energy-Based Distributed Generations
}

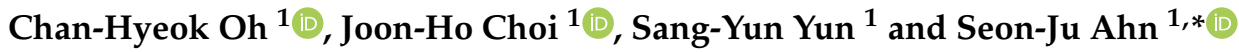 \\ Department of Electrical Engineering, Chonnam National University, Gwangju 61186, Korea; \\ dhcksgur@naver.com (C.-H.O.); joono@chonnam.ac.kr (J.-H.C.); drk9034@chonnam.ac.kr (S.-Y.Y.) \\ * Correspondence: sjahn@chonnam.ac.kr; Tel.: +82-62-530-1738
}

Citation: Oh, C.-H.; Choi, J.-H.; Yun, S.-Y.; Ahn, S.-J. Short-Term Cooperative Operational Scheme of Distribution System with High Hosting Capacity of RenewableEnergy-Based Distributed Generations. Energies 2021, 14, 6340. https://doi.org/10.3390/en14196340

Academic Editor: Gianfranco Chicco

Received: 30 August 2021

Accepted: 30 September 2021

Published: 4 October 2021

Publisher's Note: MDPI stays neutral with regard to jurisdictional claims in published maps and institutional affiliations.

Copyright: (c) 2021 by the authors. Licensee MDPI, Basel, Switzerland. This article is an open access article distributed under the terms and conditions of the Creative Commons Attribution (CC BY) license (https:// creativecommons.org/licenses/by/ $4.0 /)$.

\begin{abstract}
As the interconnection of renewable-energy-based distributed generations (DGs) to the distribution system increases, the local and temporary voltage and current problems, which are difficult to resolve with the existing operation method, are becoming serious. In this study, we propose a short-term operational method that can effectively resolve voltage and current violations caused by instantaneous output fluctuations of DGs in a system with a high hosting capacity of renewable energy sources. To achieve the objectives, a modified heuristic network reconfiguration method, and a method determining the maximum power output limit of individual DGs are proposed. We propose a cooperative method for controlling the power output fluctuations of renewable-energy-based DGs, which includes voltage control, network reconfiguration, and power curtailment. The proposed algorithm was verified through case studies by using a test system implemented in MATLAB environments. It can effectively resolve violations caused by DGs while minimizing the number of switching operations and power curtailment. The proposed method is an appropriate operation method to be applied to the real system as it can cope with the instantaneous output fluctuation of DGs, which was not dealt with in the existing operation method.
\end{abstract}

Keywords: active distribution network; hosting capacity; network reconfiguration; operational planning

\section{Introduction}

Renewable energy sources (RESs) have been increasingly used in electric power systems to reduce the consumption of fossil fuels and greenhouse gas emissions. However, RESs introduce new problems to the distribution system, such as overvoltage, overcurrent, and protection coordination failure [1]. The conventional distribution network has been designed with a fit-and-forget approach, assuming the worst scenario at the planning stage; hence, it does not require special controls [2]. Therefore, additional system infrastructure is required to address the problems introduced by the increased use of RESs. However, infrastructure reinforcement requires large investments and new site locations to expand and install new lines or facilities. However, it is difficult to secure new sites because of opposition from residents or environmental problems. Therefore, countermeasures must be taken to enhance the penetration rate of renewable energy generation with minimal investments in additional infrastructure.

The conventional operational method for distribution systems does not actively control the power system, which results in a low capacity factor. Recently, active control methods of distribution systems have been proposed to increase the penetration rate of RESs by resolving the problems caused by the increased integration of RESs [3]. Active control measures, such as voltage control, network reconfiguration, and curtailment can reduce the integration problems of RESs. Recent studies on dynamic network reconfiguration methods focused on hourly control and included the abovementioned measures as 
well as load control objectives. Existing research on network reconfigurations, including dynamic network reconfiguration, aimed primarily at loss minimization [4-7]. Silva et al. proposed a method of dynamic network reconfiguration for loss minimization and analyzed the computational time according to the algorithm execution cycle [4]. Jafari et al. conducted dynamic reconfiguration studies to improve reliability and minimize loss. Their method used a hybrid algorithm that combined an exchange market algorithm and the wild goats algorithm to improve computational speed and accuracy [5]. In addition to loss minimization, some studies focused on load balancing, voltage fluctuation minimization, and voltage profile improvement [6,7]. Furthermore, a dynamic network reconfiguration can perform more frequent switching operations than a static network reconfiguration. Therefore, some studies aimed to minimize the number of switching operations [8,9]. Fu et al. calculated the nominal hosting capacity $(\mathrm{HC})$ of each hour to evaluate the maximum RES penetration rate and derived a $24 \mathrm{~h}$ reconfiguration schedule to accommodate the capacities of all hours [8]. Peng et al. investigated dynamic network reconfiguration methods to minimize three-phase imbalance problems and the number of switching operations in a system that was integrated with various types of distributed generations (DGs) [9].

As a dynamic network reconfiguration has various applications, some studies minimized the operating cost by using cost functions [10-15]. Ameli et al. proposed a dynamic reconfiguration method to minimize the electricity cost, customer service interruption penalty, transformer life cycle cost, and switching cost [10]. In their research, scenarios were set using harmonic search, and the ant colony algorithm was used to search for an optimal solution. Esmaeili et al. developed a dynamic reconfiguration method for minimizing operational costs by accounting for the cost of the total loss, switching cost, demandresponsive load and generation cost, and the cost of exchanging power [11]. Mixed-integer linear programming was used to derive an optimal operating schedule of $12 \mathrm{~h}$, considering the hourly reconfiguration, energy storage system, and demand response. They applied model predictive control to create an hourly schedule that reflected the uncertainties.

Apart from dynamic network reconfiguration, some studies investigated cooperative control methods. Pamshetti et al. proposed a cooperative control scheme of volt-var control, network reconfiguration, and service recovery algorithms to minimize energy consumption [12]. By applying the ZIP load model, they implemented a control scheme that minimized power demand and line loss according to voltage. Murty and Sharma proposed a cooperative control method of an on-load tap changer (OLTC), DG, distribution static compensator (D-STATCOM), and network reconfiguration for voltage regulation and cost minimization [13]. In addition, they determined the optimal location of DG and D-STATCOM and analyzed the effect of cooperative control, according to the presence or absence of the regulating devices. Pilo et al. proposed a cooperative control scheme to minimize the operating cost including the power curtailment of DGs, auxiliary service, demand response, and power loss [14]. A two-stage operation plan consisting of the first stage considering only output limitation and auxiliary services and the second stage including system reconfiguration was proposed. Liu et al. proposed the optimal control method that the network reconfiguration, voltage regulator, step voltage compensator, distribution static synchronous compensators, and shunt capacitor banks to minimize the total operating cost of an unbalanced distribution network [15]. There are also studies to increase the $\mathrm{HC}$ by using the power electronic device, such as soft open point (SOP) [16]. This method alleviates the violation caused by DGs by controlling the power flow at the point using SOP instead of the existing switch of on/off method. HC can be increased by replacing frequently controlled switches with SOPs and controlling them together with other switches. However, an additional cost is required to replace the existing switches with SOPs.

These previous studies derived control solutions based on the predicted values of load and DG, which were primarily hourly predictions. However, even if the one-hour average output can be accurately predicted, it is difficult to respond to the fluctuation of RESs with hourly-forecast-based operation method. Since temporary overvoltage and 
overcurrent frequently occur when the HC increases, measures to appropriately respond to the fluctuation of RESs are required.

In this study, we propose a short-term operation planning method that can effectively respond to the output fluctuations of DGs in a distribution system with high HC of RES. The proposed method is a cooperative operation method of voltage control, network reconfiguration, and determining the maximum power output limit of individual DGs. In order to cope with the instantaneous output fluctuation of DGs, a control method with a shorter period is required. However, a control method with a shorter period is accompanied by a greater number of controls. Therefore, this study derives a control method capable of effectively resolving violations while minimizing the number of switching operations and power curtailments through the analysis of several control periods. The main contributions of this study are as follows:

(1) We developed a modified technique for heuristic network reconfiguration that can be applied to a power system integrated with multiple DG units.

(2) We developed a method for determining the maximum power output limit of individual DGs in each control period that can respond to real-time power output fluctuations of DG.

(3) We developed an optimal combination based on the performance index; our approach combined the control period, network reconfiguration, and maximum output determination methods.

The remainder of this paper is organized as follows. Section 2 summarizes the background of this research. Section 3 describes the proposed method of heuristic network reconfiguration, a method of determining the maximum output of DG, and the short-term operational methods of the distribution system. In Section 4, case studies performed using MATLAB are presented. The results of these studies verified the performance of the algorithms and short-term operational methods. Finally, Section 5 concludes this paper.

\section{Motivation of the Research}

\subsection{Necessity for Short-Term Control to Address the Fluctuations in RES Output}

Fluctuations in the power output of the RESs complicate the operation of a power system with a large RES HC. The most effective method for controlling these fluctuations is real-time control according to the state of the power system. However, a considerable amount of measurement data are needed to implement real-time control, which requires a high-performance communication infrastructure. Furthermore, this approach would involve significantly more frequent control operations than the conventional operating method, which is a challenge for practical implementations. A more realistic approach would be to perform short-term control, such as at 5 or 15 min intervals. Recently, several studies predicted photovoltaic (PV) output in a duration of several minutes, such as 5, 15, and $30 \mathrm{~min}$, instead of $1 \mathrm{~h}$. In particular, Zhou compared the accuracy for predictions made in $1,5,15,20,25$, and $30 \mathrm{~min}$. In general, the shorter the prediction period, the better the prediction accuracy [17-20].

To derive a solution for the system control, we can use the averages over a certain period for the predicted values of the load and DG output. The fluctuation of load values is not extremely large; therefore, the control solution using the average values would rarely cause a problem in system operations. However, as the RES output has large fluctuations, the control solution derived using average values may cause problems in real-time operations. This problem aggravates as the HC increases. Figure 1 compares the power output fluctuations recorded in 1 min periods and the output values averaged over 5, 15, 30, and $60 \mathrm{~min}$. The solid lines represent the output powers, and the dotted lines represent the corresponding peak values. With a longer period, the output fluctuation is less visible. Figure 2 shows the maximum current magnitude of the system averaged at 5 min (black line) and $60 \mathrm{~min}$ (red line), respectively, and the allowable current limit (blue line). No overcurrent was observed in the 60 min average, but frequent overcurrent was observed in the 5 min average. Thus, overcurrent can occur frequently if the system 
is operated using measurements averaged over $60 \mathrm{~min}$ without other means of control. Therefore, short-term control should consider several-minute cycles instead of one-hour periods, and control measures need to respond to fluctuations in the RES output.

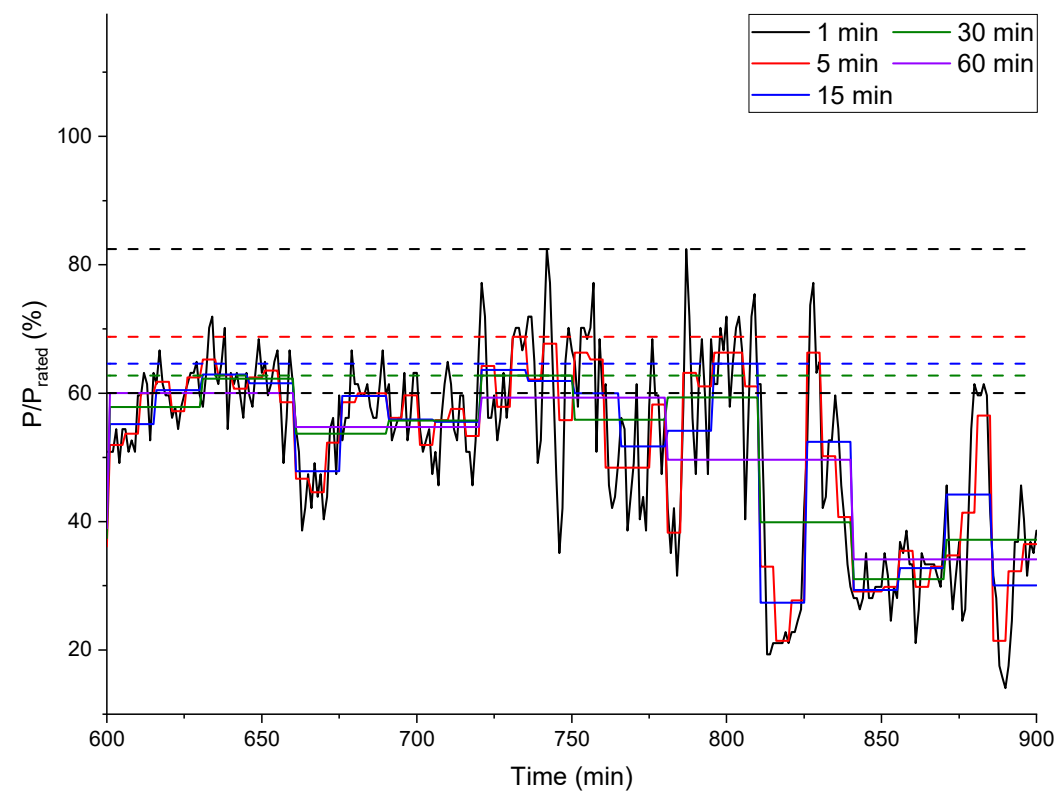

Figure 1. Comparison of power output fluctuations with control periods of 1, 5, 15, 30, and $60 \mathrm{~min}$.

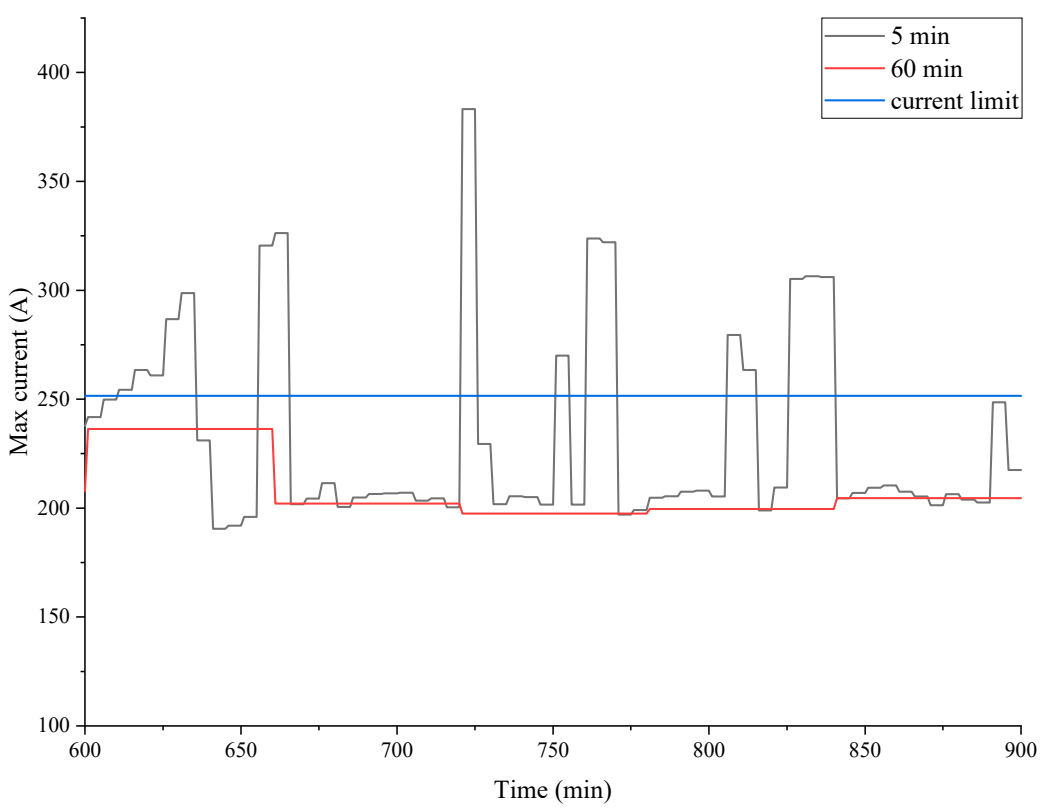

Figure 2. Comparison of current magnitudes between 5 and $60 \mathrm{~min}$ average power output.

\subsection{Necessity for a Network Reconfiguration Method Suitable for Local Controllers}

Network reconfiguration is essential to effectively control power output fluctuations of RESs in a system with high HC. The conventional method of network reconfiguration derives the optimal topology for a wide range of distribution systems from the central operation system. In recent years, along with the increase in the integration of RESs in distribution systems, methods of deriving an hourly topology operation schedule were investigated using the day-ahead forecasting of the DG power output. These methods primarily use predicted values on an hourly basis to provide the upcoming 24-h topology operation schedule for each period. The time margin for creating this schedule is large, 
which indicates a low restriction on the computational time. However, the control solutions must be computed quickly for shorter periods, such as 5 or $15 \mathrm{~min}$. In addition, the required control period for responding to power output fluctuations of the RES is shorter and the amount of data are larger than in conventional control solutions. Consequently, deriving control solutions for all topologies in a central system is not practical. Therefore, effective responses to the power output fluctuations in RESs require data collection and the derivation of a control solution from the local controllers that can operate at the substation or bank level. Therefore, we need a network reconfiguration method that is less computationally intensive, can operate in local controllers, and can quickly derive a control solution.

\section{Proposed Cooperative Operational Method}

We propose a cooperative method for controlling the power output fluctuations of RESs, which includes voltage control, network reconfiguration, and power curtailment. Each control measure is applied according to the power output of the RES and the state of the system. Figure 3 shows a conceptual diagram of the operational method. Using the predicted values of the load and power output of the next period, we calculate the values of the OLTC tap control, system topology, and maximum power output limit of DGs. Subsequently, when the next control period starts, we control the topology and OTLC tap according to the operating solution and adjust the maximum output of the RES during this period.

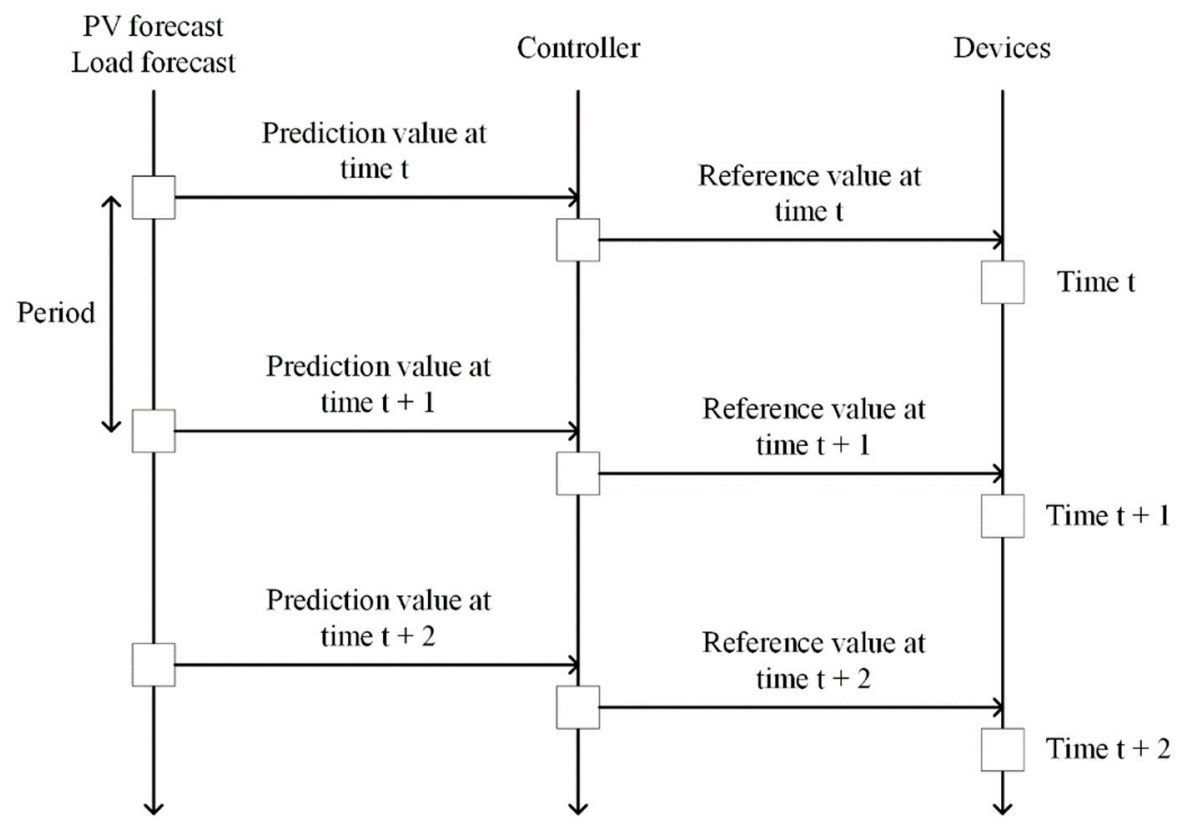

Figure 3. Control sequence of the proposed operational methods.

This section presents a summary of the method, and the following subsections explain individual algorithms. Figure 4 shows the flowchart of the proposed method. The predicted data of DG and load of the next control period are used as input, and the system state of the next period is predicted using the power flow calculation. The method determines whether an overvoltage, undervoltage, or overcurrent violation occurs. Voltage control is performed if a voltage violation occurs without an overcurrent violation. If the result of the power flow calculation shows an occurrence of overcurrent, the algorithm determines whether the overcurrent is caused by the load or by the DG. In the case of overcurrent caused by DG, if the magnitude of overcurrent does not exceed a certain range of the current limit value, the overcurrent violation is resolved using DG output curtailment. If the overcurrent is caused by the load or if the magnitude of the overcurrent exceeds a set range, a network reconfiguration solution is derived to resolve or mitigate the overcurrent 
problem. The algorithm determines whether voltage violation will occur in the system after reconfiguration; if necessary, a voltage control solution is derived. Subsequently, the algorithm for specifying the maximum output range of each DG in the next period is executed based on the current topology. Finally, the OLTC tap control solution, network reconfiguration solution, and maximum output value of each DG are saved, and the algorithm is terminated.

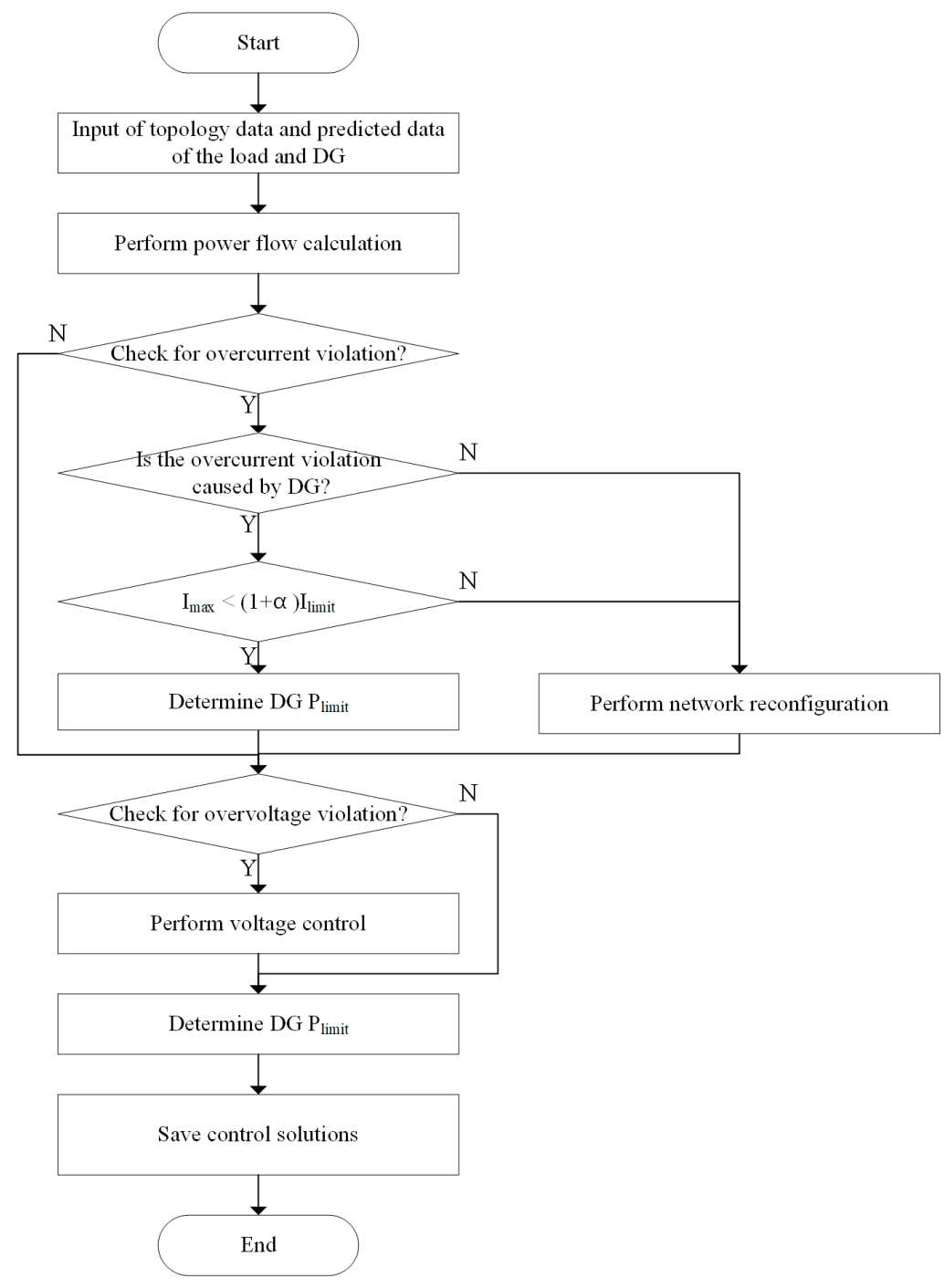

Figure 4. Flowchart of the proposed operational method.

The proposed operational method requires more frequent control actions than those in the conventional method. The control of the active and reactive power of the inverter, which has a relatively low risk of control failure, does not pose a significant problem for the system operator even if the control is performed frequently. However, in the event of control failure in OLTC tap control or switches, the failure may have a direct adverse impact on the system. Furthermore, the maximum number of switching actions for these devices is limited by the service life of the devices. Consequently, frequent switching control may cause severe problems for the system operator. Therefore, in this study, we apply measures to prevent the frequent control of OLTC taps and switches. During voltage control, the OLTC control is performed only when the solution could not be obtained by controlling the reactive power of DG alone. A margin factor $\alpha$ is applied to the allowable current limit condition to reduce the number of switch control operations. With the application of the margin factor $\alpha$ and the allowable current value of $I_{\text {limit }}$, the network 
is not immediately reconfigured when the maximum current of the system exceeds $I_{\text {limit }}$. Instead, we reconfigure the network when the maximum current of the system exceeds $I_{\text {limit }} \times(1+a)$. This allows for more stringent conditions for network reconfiguration, reducing the frequency of network reconfigurations.

\subsection{Power Flow Equation}

In this study, the result of power flow calculation using the predicted load and DG output are used as the system state for determining the control solutions. The power flow solution is based on the Newton-Raphson method implemented in the MATPOWER package [21]. The active and reactive power of node $i$ are defined as Equations (1) and (2), respectively.

$$
\begin{gathered}
P_{i}=\sum_{k=1}^{N}\left|Y_{i k}\right|\left|V_{k}\right|\left|V_{i}\right| \cos \left(\theta_{i k}-\delta_{i}+\delta_{k}\right), \\
Q_{i}=-\sum_{k=1}^{N}\left|Y_{i k}\right|\left|V_{k}\right|\left|V_{i}\right| \sin \left(\theta_{i k}-\delta_{i}+\delta_{k}\right)
\end{gathered}
$$

where $i$ and $k$ are the bus indices, $N$ is the number of nodes, $\left|Y_{i k}\right|$ and $\theta_{i k}$ are magnitude and angle of the element $Y_{i k}$ of admittance matrix. $\left|V_{i}\right|$ and $\left|V_{k}\right|$ are the voltage magnitudes and $\delta_{i}$ and $\delta_{k}$ are the phase angles of node $i$ and $k$, respectively. Based on Equations (3) and (4), the Jacobian matrix gives the linearized relationship between small changes in voltage angle and voltage magnitude with the small changes in real and reactive power. It can be expressed as Equation (3).

$$
\left[\begin{array}{c}
\Delta P \\
\Delta Q
\end{array}\right]=\left[\begin{array}{cc}
J_{1} & J_{2} \\
J_{3} & J_{4}
\end{array}\right]\left[\begin{array}{c}
\Delta \delta \\
\Delta|V|
\end{array}\right]
$$

\subsection{Voltage Control Method}

In this study, we applied the voltage control method proposed in [22]. This method controls the voltage using the tap control of OLTC, the step voltage regulator, and reactive power control of DGs in the distribution system. In prior work, the optimal solution was derived without distinguishing the priorities of tap control and reactive power control. However, in this study, our first approach is to resolve the voltage violation using the reactive power control of DG alone to minimize the number of OLTC tap controls. Only when the problem is not resolved using this approach, we concurrently perform both the OLTC and reactive power control to resolve the voltage violation problem. The objective function for the voltage control is defined as Equation (4) to maintain the voltages of all nodes as close to the nominal voltage as possible.

$$
\min O F=\sum_{i=1}^{N}\left(V_{i}-V_{\text {rat }}\right)^{2},
$$

where $V_{i}$ is the voltage value of the ith node, $V_{\text {rat }}$ is the nominal voltage, and $N$ is the number of nodes. Figure 5 shows the flowchart of voltage control. 


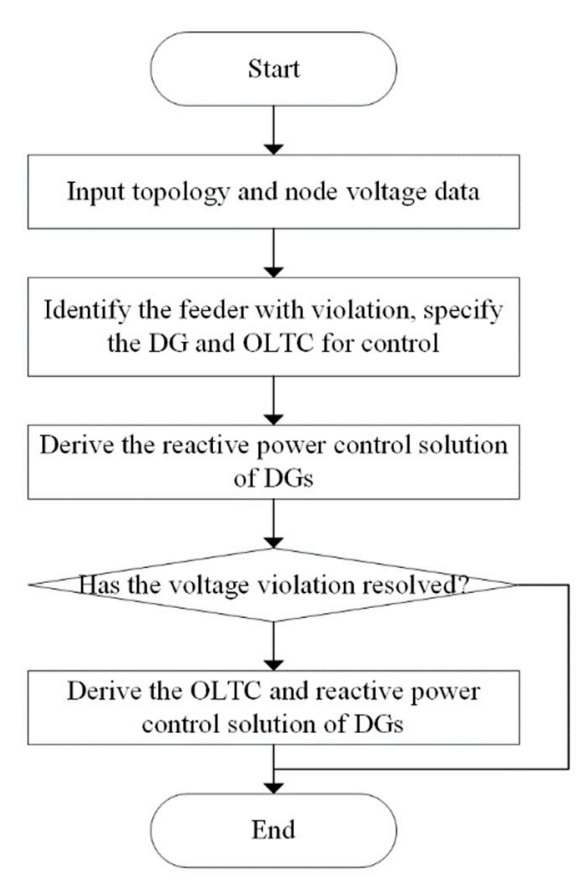

Figure 5. Flowchart of the voltage control process.

\subsection{Dynamic Network Reconfiguration Method}

The network reconfiguration algorithm derives a control solution by acquiring data from the local controller, as described in the previous section. It is important to provide the solution quickly if this algorithm controls systems with a large RES HC. Therefore, we developed a heuristic method that can derive the solution quickly. The conventional heuristic methods for network reconfiguration made a loop by closing an open switch, and then opened a switch where the minimum current flows in the loop [23-26]. This conventional method derives solutions for distribution networks with load only. In such a system, there is only one location at which the direction of the loop current changes, as shown in Figure 6a. The point at which the current flow is changed is the same as the point at which the minimum current flows. Therefore, the accuracy of the existing heuristic method is relatively high in a load-only system. However, when DGs are connected to the distribution network, the loop current becomes more complicated than that in the load-only network; therefore, the conventional heuristic method is not adequate. Figure $6 \mathrm{~b}$ shows the loop current in a DG-connected system. Even in the case of adding only one DG to the system, the current direction can change at up to three points. This situation becomes even more complicated with an increased number of DGs integrated into the system; hence, it becomes impractical to apply the existing heuristic method. Therefore, in this study, we set the switches adjacent to the current-flow-changing point as the open switch candidates. Among the candidate switches, we select a switch that minimizes the performance index (P.I. $\left.\cdot_{N R}\right)$ value in Equation (5) as the open switch. The performance index aims to resolve the voltage and current violations, maintain the voltage of each node as close to the nominal value as possible, and achieve a uniform distribution of the current flow in each section.

$$
\text { P.I.NR }=\omega_{v} \sum_{i=1}^{N}\left(V_{i}-V_{\text {rat }}\right)^{2}+\omega_{i} \sum_{j=1}^{M}\left(\frac{I_{j}}{I_{\text {limit }}}\right)^{2}+\rho_{O C},
$$

where $I_{j}$ is the current in section $j, I_{\text {limit }}$ is the current limit value, $M$ is the number of sections; $\omega_{v}$ and $\omega_{i}$ are the weights for the voltage and current, respectively, and $\rho_{O C}$ is the penalty in the case of overcurrent. 


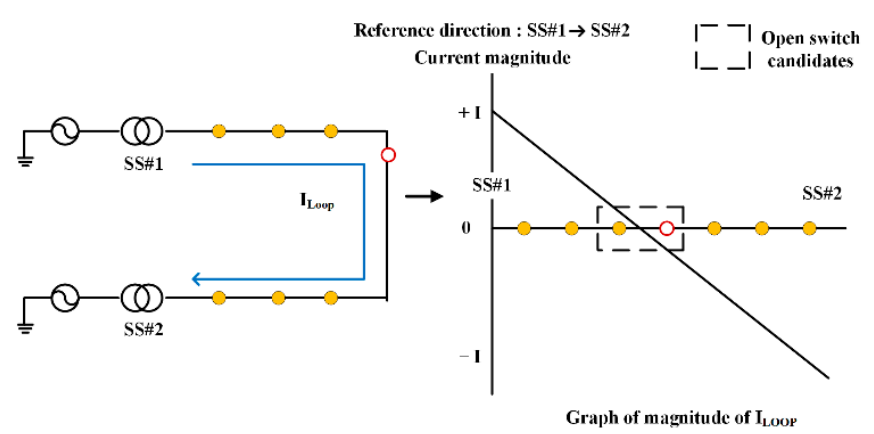

(a)

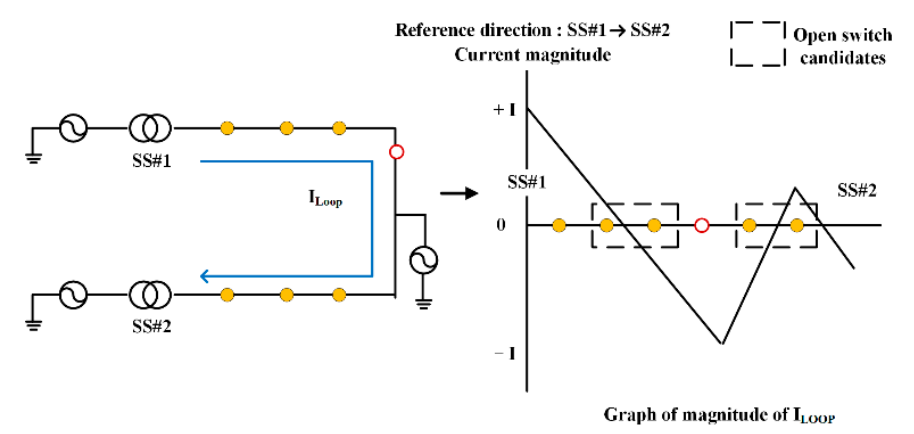

(b)

Figure 6. Current patterns in the loop with DG integration: (a) loop with loads only; (b) loop with DG.

The proposed network reconfiguration algorithm is based on Zin's method [26], except for the method of selecting the open switch candidates, as described above. The proposed algorithm is as follows, and its flowchart is presented in Figure 7.

(1) The system data are received as input, and a set of open switches in the system is determined.

(2) A loop is created by closing the first switch from the open switch set, and the switch is removed from the open switch set. The loop current pattern generated by closing the open switch is analyzed to determine the point of change in the current flow direction in the loop.

(3) All switches adjacent to the current flow change point are selected as open switch candidates, each candidate switch is opened, and the open switch is added, which minimizes the performance index to the end of the open switch set.

(4) Repeat steps 2-3, and if the closed switch and the opened switch are the same, this is counted.

(5) When the number of closed and open switches is equal to the number of switches in the open switch set, the open switch set is saved, and the algorithm is terminated.

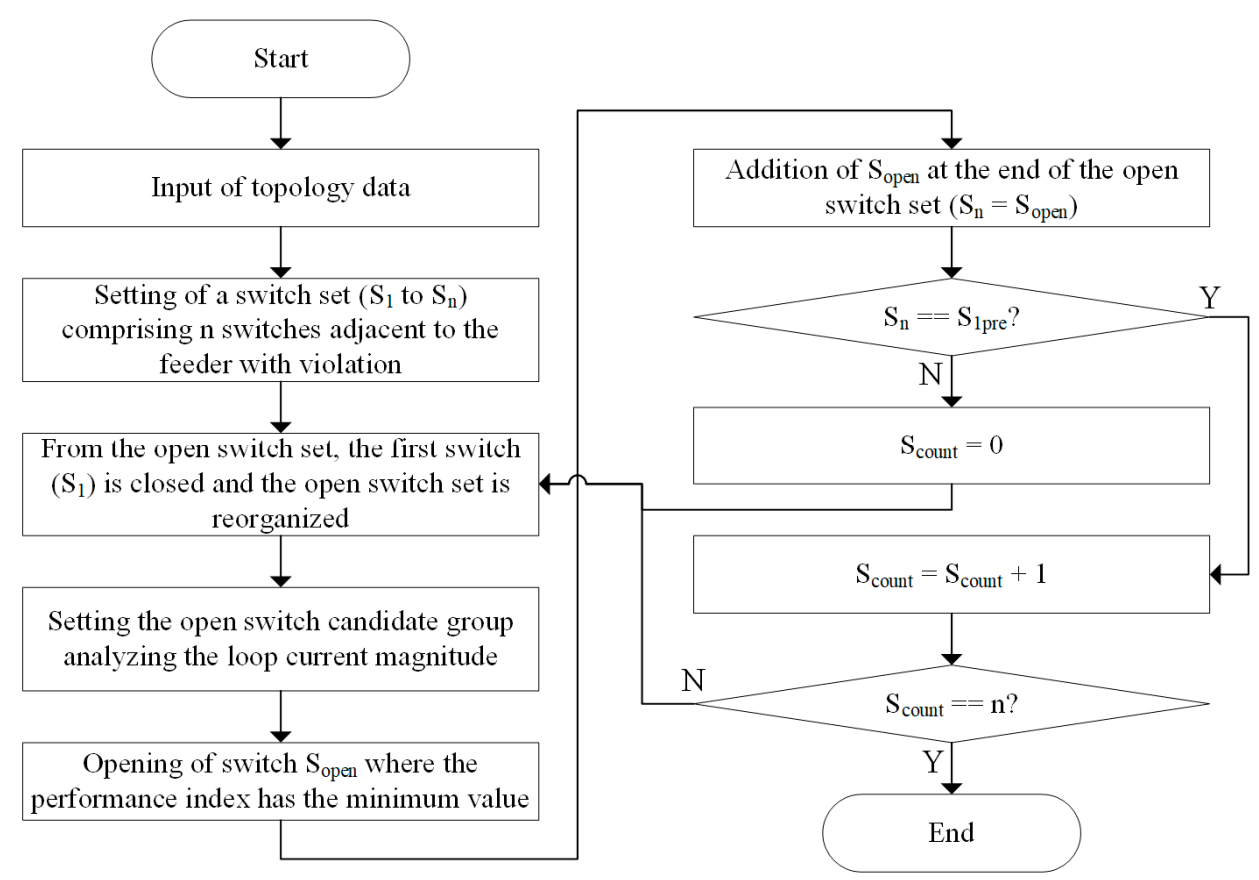

Figure 7. Flowchart of the network reconfiguration. 


\subsection{Method of Designating the Maximum Power Output Limit of DGs}

In the recently developed grid-connected inverter, the active power output can be controlled so that it is the maximum power output limit set for a specific period, as shown in Figure 8 [27,28].

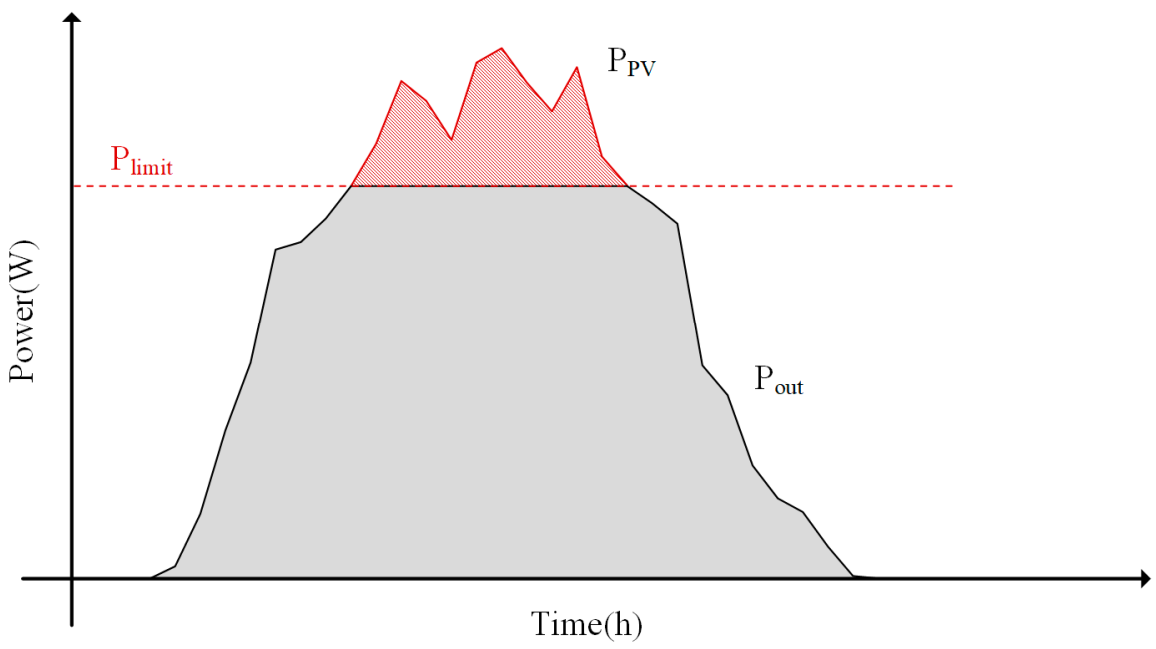

Figure 8. Conceptual diagram of determining the maximum power output limit.

The following method determines the maximum output limit of each DG to prevent overcurrent in the system with multiple DGs.

(a) Method of determining the representative section.

The current magnitude of all line sections should be analyzed to designate the allowable output range of DGs. However, in a radial distribution system with only loads and DGs, the maximum output of each DG can be determined by the current analysis of specific sections. The overcurrent caused by DGs occurs when more current is generated than can be consumed by the load. Therefore, the overcurrent flows in the reverse direction toward the feeder terminal. Among the possible current combinations of each DG, the largest magnitude of current flows in the line section farthest from the feeder terminal, as marked with a red line in Figure 9. These sections are defined as representative sections.

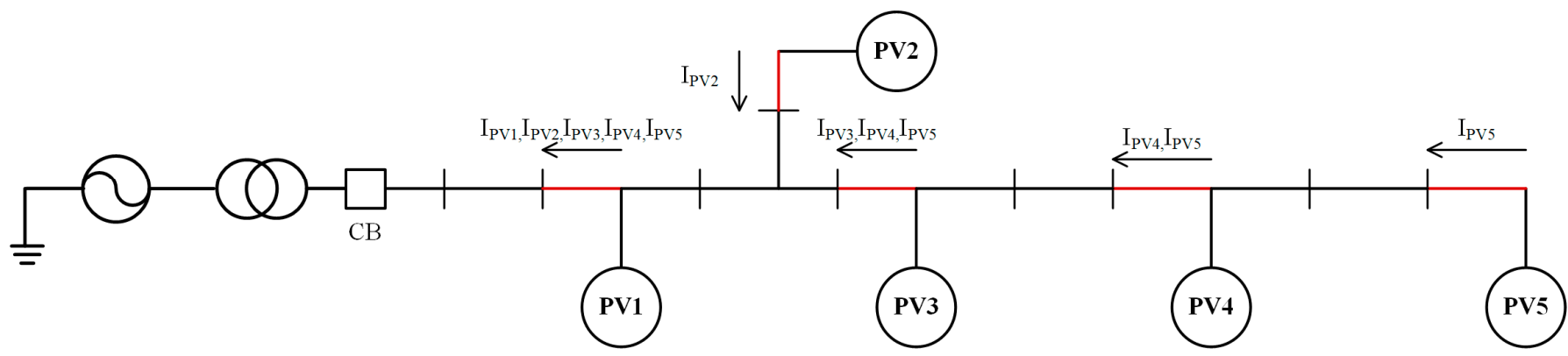

Figure 9. Current supply mode of PV.

If the power output of DGs is controlled to prevent overcurrent in the representative sections, there will be no overcurrent in the other sections of the system. Therefore, we analyze only the current magnitude of the representative sections when designating the maximum power output of each DG.

Figure 10 shows the flowchart of the algorithm for selecting the representative sections in each feeder. First, we identify the DG nodes connected to k-th feeder. Next, the line sections in the path from the $\mathrm{k}$-th feeder terminal to each DG node are identified and saved as $\Omega_{\text {path, }}^{k}$. Using this information, we identify the DGs that affect the current of each 
section and save the corresponding DG set. Among the sections that have the same DG set, we select the farthest section from the feeder terminal and save it as an element of the representative sections of the $\mathrm{k}$-th feeder $\left(\Omega_{\text {line,rep }}^{k}\right)$. The DG set of the $\mathrm{n}$-th element of $\Omega_{\text {line,rep }}^{k}$ is denoted as $\Omega_{D G, n}$. The representative sections are updated whenever the topology is changed by the network reconfiguration.

(b) Method of determining the maximum power limit of individual DGs.

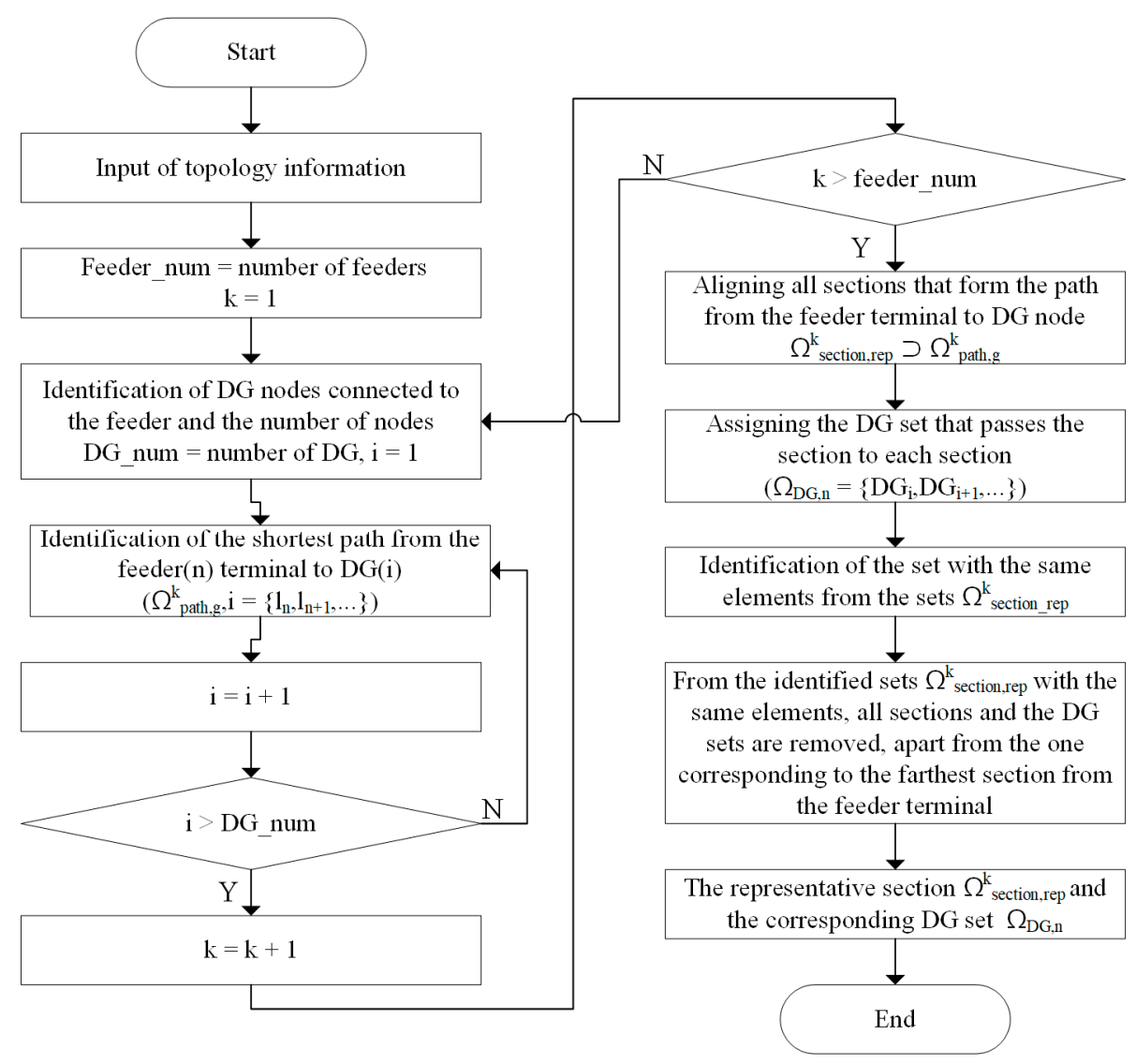

Figure 10. Flowchart for deriving a representative section.

The maximum power limit in the corresponding control period of each DG is calculated using the current of the representative section and the maximum allowable current. As the active power curtailment value of the DG needs to be calculated, only the real part of the current is used for calculation based on the current in the representative section, as shown in Figure 11. In this figure, $I_{n}, I_{n, R}$, and $I_{n, X}$ represent the magnitude of current in the representative section $\mathrm{n}$ and its real and imaginary components, respectively. $I_{n}^{\text {limit }}$ and $I_{n, R}^{\text {limit }}$ are the magnitudes of the maximum allowable current and its real component, respectively, in the representative section. We can assume that the change in the imaginary component $\left(I_{n, X}\right)$ of the current in the representative section during the control period is insignificant. Therefore, the difference $\Delta I_{n, R}$ between $I_{n, R}$ and $I_{n, R}^{\text {limit }}$ is distributed to each DG to calculate the allowable output range of DG. As shown in Figure 11a, if $I_{n}$ does not exceed $I_{n}^{\text {limit }}$, the excess current is distributed to each DG, and the maximum power limit of each DG will be set higher than the expected output. As shown in Figure 11b, if $I_{n}>I_{n}^{\text {limit }}$, the maximum power limit of each DG will be set lower than the expected output. From Figure 11, the real component $\left(\Delta I_{n, R}\right)$ of the current difference in the representative section $\mathrm{n}$ can be derived using Equation (6).

$$
\Delta I_{n, R}=\sqrt{\left(I_{n}^{\text {limit }}\right)^{2}-\left(I_{n, X}\right)^{2}}-I_{n, R}
$$




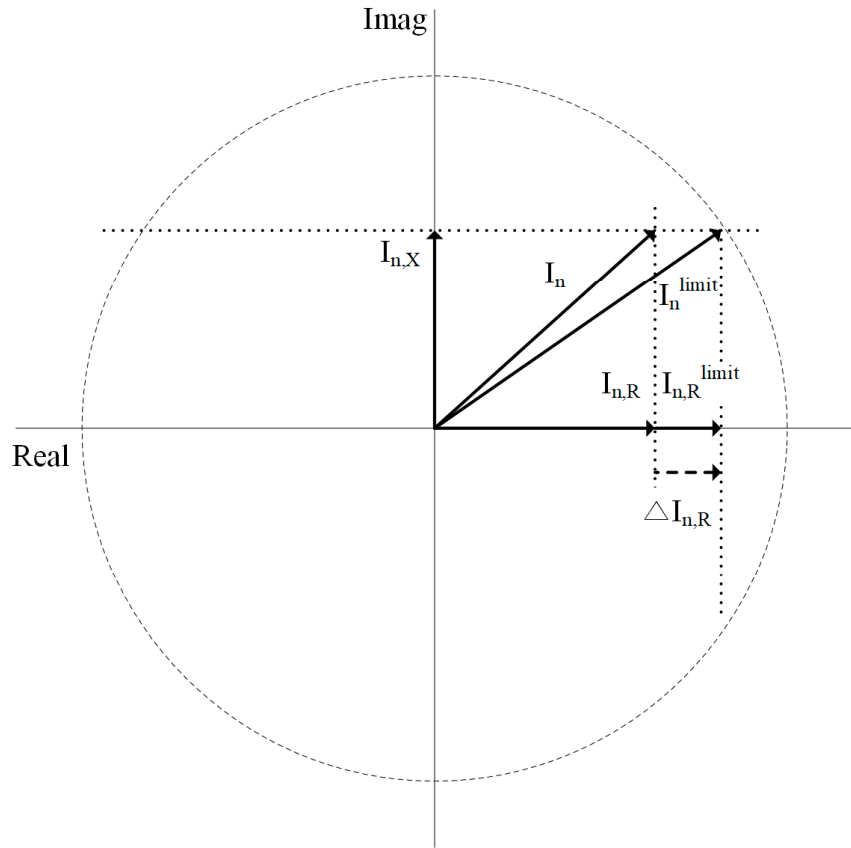

(a)

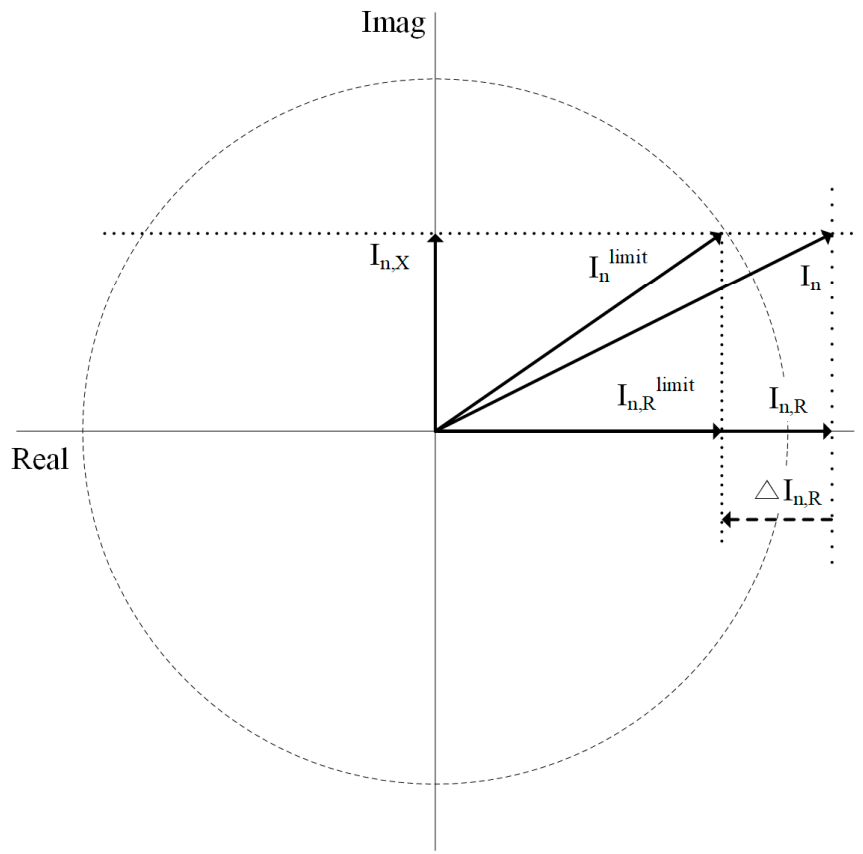

(b)

Figure 11. Vector diagram for $\Delta I_{n, R}$, the difference between the current in the representative section and the maximum current limit: (a) $\Delta I_{n, R}$ when $I_{n}$ is within the limit; (b) $\Delta I_{n, R}$ when $I_{n}$ exceeds the limit.

The maximum power limit of each DG is calculated as follows. The real component of the current difference in the representative section is distributed to DGs that affect the current in the section according to the rated capacity $\left(S_{g}^{r a t}\right)$. The real component of the maximum output current of the $\mathrm{g}$-th DG $\left(I_{g, R}^{\text {limit }}\right)$ can be defined as the sum of the real components of the output current of each DG $\left(I_{g, R}\right)$ and the distributed difference in current in the section. Therefore, the allowable power limit $\left(P_{g, n}^{\text {limit }}\right)$ considering the current difference in the representative section $n$ of the gth DG can be calculated using the voltage $\left(V_{g}\right)$ of the connected node and $I_{g, R}^{\text {limit }}$, as shown in Equations (7) and (8). The DG that does not correspond to the DG set $\left(\Omega_{D G, n}\right)$ of the representative section $\mathrm{n}$ does not affect the current in the section; thus, the maximum power limit of the DG is set as the rated capacity.

$$
\begin{aligned}
& I_{g, R}^{\text {limit }}=I_{g, R}+\Delta I_{n, R} \times \frac{S_{g}^{\text {rat }}}{\sum_{g \in \Omega_{D G, n}} S_{g}^{\text {rat }}} \\
& P_{g, n}^{\text {limit }}= \begin{cases}V_{g} \times I_{g, R}^{\text {limit }} & \text { if } g \in \Omega_{D G, n} \\
S_{g}^{\text {rat }} & \text { otherwise }\end{cases}
\end{aligned}
$$

Power output fluctuations of one DG can affect the current in several representative sections. Therefore, the minimum among $P_{g, n}^{\text {limit }}$ values, calculated by considering all the representative sections in the feeder, is set as the final allowable range of power $\left(P_{g}^{\text {limit }}\right)$ of the gth DG, as shown in Equation (9).

$$
P_{g}^{\text {limit }}=\min _{n \in \Omega_{\text {line,rep }}^{k}}\left(P_{g, n}^{\text {limit }}\right)
$$

\section{Simulation Results}

The test system used in the simulation was a radial distribution system with two substations and five feeders, as shown in Figure 12. The test system included 187 nodes and 192 branches, and the parameters of switch configuration and the line were selected by 
reflecting the actual distribution system characteristics of Korea Electric Power Corporation (KEPCO) (Naju-si, Korea) [29]. The nominal voltage was $22.9 \mathrm{kV}$, the line was set to ACSR $160 \mathrm{~mm}^{2}$, the impedance was $0.1823+\mathrm{j} 0.3901 \Omega / \mathrm{km}$ in all sections of the line, and the maximum allowable current was $251.6 \mathrm{~A}$, corresponding to the rated capacity of 10 MVA. For the operating range of voltage, the minimum voltage was 0.96 p.u., and the maximum voltage was 1.02 p.u. For the load pattern, we used the representative patterns for residential, commercial, and industrial load provided by KEPCO by season and by day of the week. For the output pattern of the PV system, we used the actual measured values in one-minute periods over 1 year of the PV system installed on the campus. In the test system, feeders \#1, \#2, and \#5 were set as medium-to-long-distance feeders with a large PV HC, and mainly included residential and industrial loads. Feeders \#3 and \#4 were set as short-distance lines with a concentration of commercial loads. The HC is defined as $100 \%$ when a PV of $10 \mathrm{MW}$ is installed to each of the $\# 1, \# 2$, and $\# 5$ feeders. To verify the effect of mitigating congestion caused by DG, we performed the simulation for 38 days in a year with a high PV generation output.

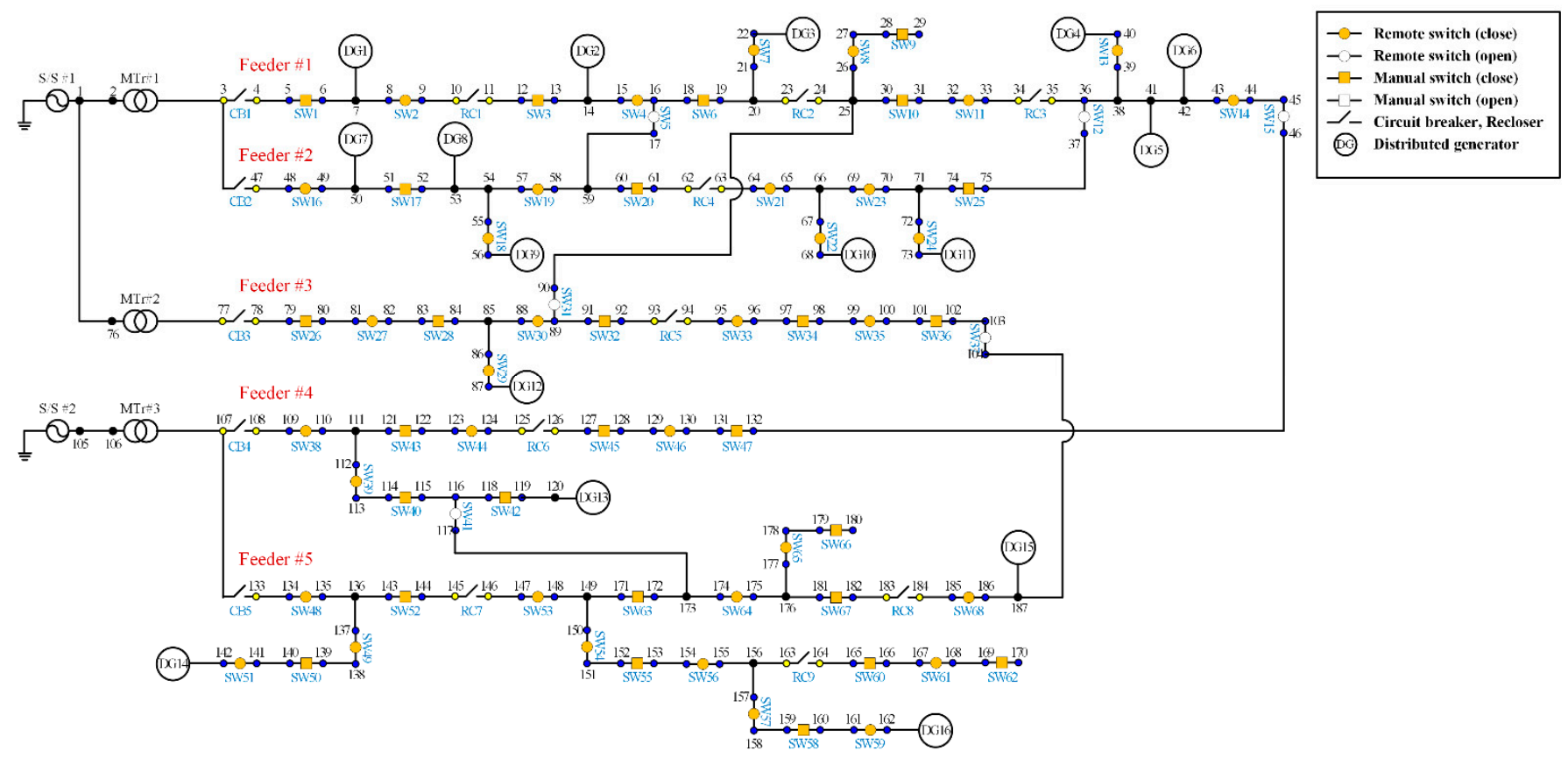

Figure 12. Test system.

The simulation was performed for three cases. In Case 1, to verify the performance of the proposed dynamic reconfiguration algorithm, we compared the existing heuristic method [26] and the binary particle swarm optimization (BPSO) method [30]. In Case 2, to verify the effectiveness of the proposed short-term operational method, we analyzed the number of switching operations and DG curtailment by changing the value of $\alpha$, the condition for relaxing the application of reconfiguration, and the control period. Finally, in Case 3, we compared the increments in output and in curtailment according to an increase in the HC to analyze the expected increase in output when integrating additional RESs when the HC in the system was already high.

We did not analyze the uncertainty in load and PV output prediction. Load fluctuation is not large when the duration of the control period is on the order of a few minutes, and the accuracy of short-term load prediction is very high. Consequently, it is reasonable to assume that the load is almost constant during the control period. The accuracy in the prediction of PV output has been improved in recent studies; in particular, shortterm output prediction when the time unit is in minutes for the immediate future has a considerably high accuracy [31,32]. Even if the actual PV output is different from the 
predicted value, the short-term variability can be controlled by the proposed curtailment method to resolve any problems caused by line overcurrent and voltage violations.

\subsection{Performance Verification of the Proposed Heuristic Algorithm for Network Reconfiguration}

We compared several methods for selecting the open switch candidates in the loop. In the simulation, we changed the number and capacity of DGs integrated into a 22-bus system, which is shown in Figure 13. For the location of DG installation in each scenario, we considered all possible installation combinations in 20 nodes, except for nodes \#1 and $\# 12$, which are slack buses. The following four methods were compared for determining the open switch candidates:

- Method 1: one point where the magnitude of the current is minimum [26].

- Method 2: the point where the magnitude of the current is minimum, and the switches at both ends.

- Method 3: the point where the current sign changes.

- Method 4: the point where the current sign changes, and the switches at both ends (proposed).

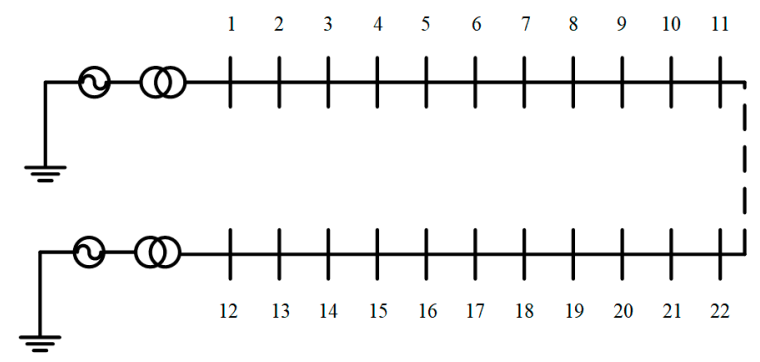

Figure 13. Simple 22-bus distribution system.

The optimal and suboptimal solutions were derived by calculating the performance index (described in Equation (5)) while opening all possible switches one-by-one in each scenario and method. Table 1 shows the probability of finding the optimal solution and the probability of finding either an optimal or a suboptimal solution for each method described above. When we apply method 1 , which uses the conventional approach, the probability of finding the optimal solution is very low (15\% to $25 \%$ ), and it is only $30 \%$ to $50 \%$ if we include suboptimal solutions. By changing and expanding the candidates of the open switches to the points of the current change and the adjacent switches, the probability of finding the optimal solution increases to $80 \%-93 \%$. If we include suboptimal solutions, it increases to $95 \%-100 \%$. Compared with the other methods, method 4 may require increased computational time because it has to search within an increased number of candidate switches. However, the computational load does not increase significantly because the process of searching the candidate switches is a simple search using a magnitude comparison.

We performed the simulations on the test system shown in Figure 13 to verify the performance of the proposed heuristic method for network reconfiguration. The computer used for the simulation had an i7-7700 $3.60 \mathrm{GHz}$ processor and a memory of $16 \mathrm{~GB}$. In the system with $\mathrm{HC}=250 \%$, the simulation was performed for the time period in which a network reconfiguration was required when the PV output was the largest during the day for 38 days. We compared the performance of the proposed method, BPSO [30], and the conventional heuristic method [26] in terms of the performance index presented in Equation (5) and computational time. Figure 14 shows the performance index values and computational time for the simulation results for 38 days, and Table 2 lists the average values of each evaluation index. In all simulation cases, the values of P.I.NR are significantly lower in the proposed method compared with those in the conventional heuristic method [26], but are slightly higher than those from the BPSO. In addition, the computational time of the proposed method is significantly reduced compared with that of the BPSO. The proposed 
method could derive a solution closer to the optimal solution at a much faster rate than that of the BPSO. Therefore, the proposed method is suitable for the situations in which a control solution must be computed rapidly by a local controller with a relatively low computational capacity in a distribution system with a large HC of DG.

Table 1. Probabilities of finding optimal and suboptimal solutions using each compared method.

\begin{tabular}{|c|c|c|c|c|c|c|c|c|}
\hline & \multicolumn{2}{|c|}{$\begin{array}{c}1 \mathrm{DG} \\
(8 \mathrm{MW})\end{array}$} & \multicolumn{2}{|c|}{$\begin{array}{c}2 \mathrm{DG} \\
(5 \mathrm{MW}, 5 \mathrm{MW})\end{array}$} & \multicolumn{2}{|c|}{$\begin{array}{c}2 \mathrm{DG} \\
(7 \mathrm{MW}, 3 \mathrm{MW})\end{array}$} & \multicolumn{2}{|c|}{$\begin{array}{c}3 \text { DGs } \\
(5 \mathrm{MW}, 3 \mathrm{MW}, 7 \mathrm{MW})\end{array}$} \\
\hline \multirow{2}{*}{$\begin{array}{c}\text { \# Of } \\
\text { Simulation } \\
\text { Cases }\end{array}$} & \multicolumn{2}{|c|}{20} & \multicolumn{2}{|c|}{190} & \multicolumn{2}{|c|}{380} & \multicolumn{2}{|c|}{1140} \\
\hline & Optimal (\%) & $\begin{array}{c}\text { Optimal + } \\
\text { Suboptimal } \\
(\%)\end{array}$ & Optimal (\%) & $\begin{array}{c}\text { Optimal + } \\
\text { Suboptimal } \\
(\%)\end{array}$ & Optimal (\%) & $\begin{array}{c}\text { Optimal + } \\
\text { Suboptimal } \\
(\%)\end{array}$ & Optimal (\%) & $\begin{array}{c}\text { Optimal + } \\
\text { Suboptimal } \\
(\%)\end{array}$ \\
\hline Method 1 & 25.0 & 45.0 & 15.2 & 32.6 & 14.7 & 31.8 & 25.5 & 49.1 \\
\hline Method 2 & 60.0 & 65.0 & 27.4 & 57.4 & 30.0 & 57.1 & 37.6 & 65.6 \\
\hline Method 3 & 30.0 & 60.0 & 43.2 & 69.5 & 36.6 & 62.9 & 62.1 & 84.7 \\
\hline Method 4 & 80.0 & 95.0 & 88.9 & 100 & 85.5 & 98.4 & 93.0 & 99.5 \\
\hline
\end{tabular}

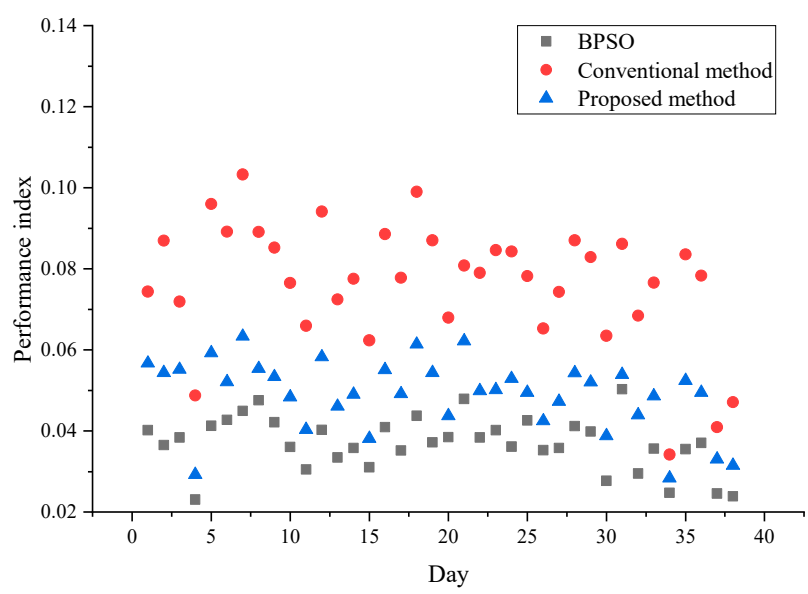

(a)

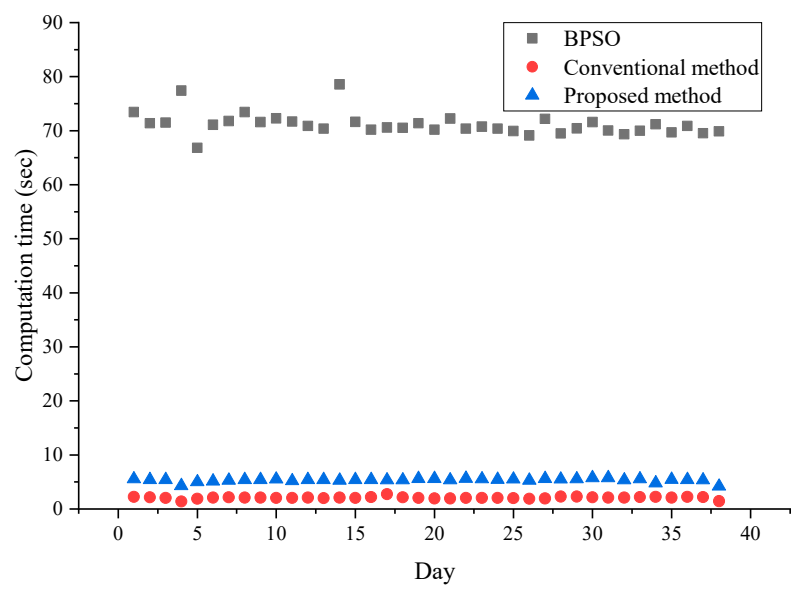

(b)

Figure 14. Simulation results of the BPSO, conventional heuristic method, and proposed method: (a) performance Index; (b) computational time.

Table 2. Comparison of the average values of performance index and the computational time for each method

\begin{tabular}{ccc}
\hline Method & $\begin{array}{c}\text { Average Value of the } \\
\text { Performance Index }\end{array}$ & $\begin{array}{c}\text { Average Value of } \\
\text { Computational Time (s) }\end{array}$ \\
\hline Conventional Method [26] & 0.077 & 2.09 \\
BPSO [30] & 0.037 & 71.15 \\
Proposed method & 0.049 & 5.37 \\
\hline
\end{tabular}

\subsection{Effect of the Control Period and Parameter Setting}

Figure 15a shows the PV data for the 33rd day with $\mathrm{HC}=250 \%$ and Figure $15 \mathrm{~b}$ shows the maximum current in a section of the system without network reconfiguration and curtailment control. An overcurrent exceeding the maximum allowable current occurs frequently between 11:00 and 14:00, the hours of high PV power generation; an overcurrent up to $180 \%$ of the current limit can be seen. Figure 16 shows the results of applying network reconfiguration and curtailment control, assuming that real-time control is possible whenever a violation occurs. Figure 16a shows the results for the following case: in the event of an overcurrent, network reconfiguration is performed first, and the unresolved overcurrent is resolved by DG power curtailment. All events of overcurrent violation are 
resolved. However, large fluctuations in the PV output led to frequent and unnecessary network reconfigurations, excessively increasing the number of switching operations. Figure $16 \mathrm{~b}$ shows the result when only DG curtailment was applied without changing the system configuration. In this case, all events of overcurrent violation were resolved; however, excessive PV curtailments occurred. On that day, $2.81 \%$ of the available generation had to be curtailed. In particular, at $13,10.8 \%$ of the available PV generation had to be curtailed to solve the problem of overloading.

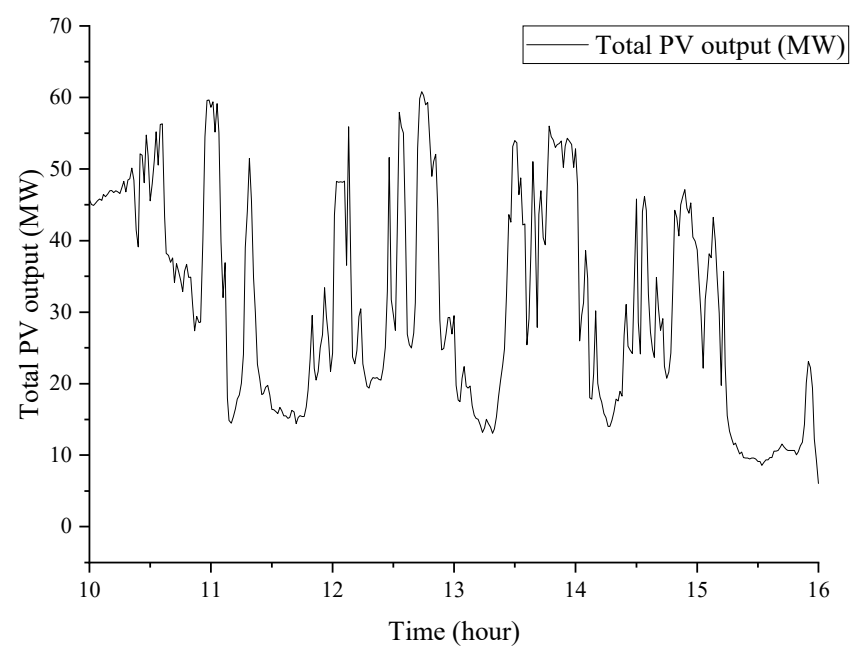

(a)

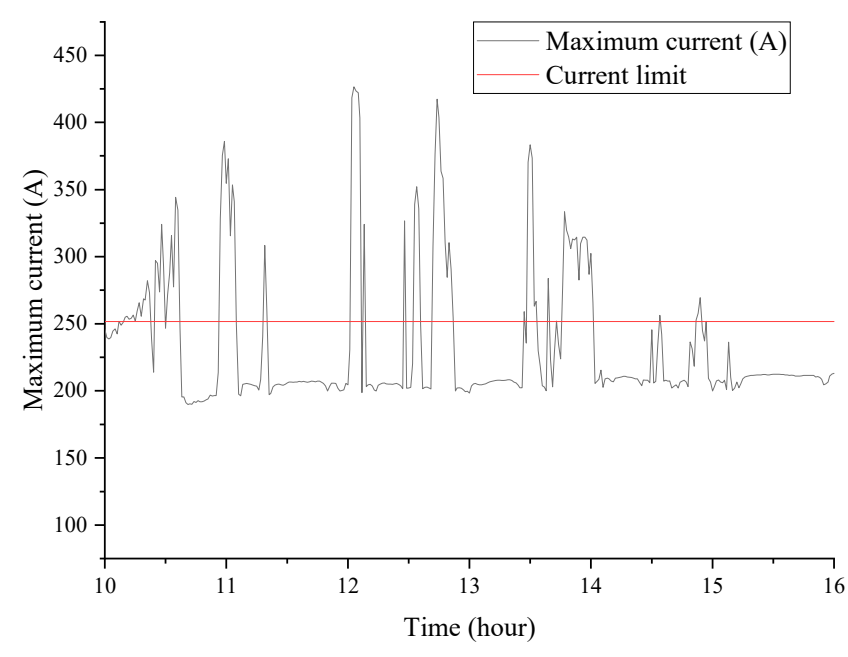

(b)

Figure 15. Profile on the 33rd day: (a) PV pattern; (b) maximum current in the system.

In this context, if the system configuration is changed whenever an overcurrent is expected, unnecessary switching occurs even if the overcurrent can be resolved with a small percentage of DG curtailment. In contrast, if reconfiguration is not performed, a significant percentage of curtailment is continuously required even for overcurrent violations that could otherwise be resolved by changing the system configuration; this can greatly compromise the operational efficiency of renewable energy service providers. Thus, the results confirm that appropriate cooperative operation is required to adjust the priority of network reconfiguration and curtailment control according to the expected magnitude of overcurrent.

In our simulations, we also analyzed the effect of the margin factor $\alpha$ and the control period setting in the proposed operating method. The control periods $(\Delta T)$ were set to $5,15,30$, and $60 \mathrm{~min}$, and the control solution of the next period was derived using the average load and PV power output prediction for each control period. Moreover, $\alpha$ values were changed to $0,0.1,0.2$, and 0.3 .

Figure 17 shows the simulation results with $\Delta T$ of $15 \mathrm{~min}$ using the data for the 4th and 33rd days to analyze the effect of $\alpha$. Figure 17a shows the magnitude of the maximum section current of the system analyzed using the predicted data before deriving the control solution, using the data for the 4th day. The expected maximum current at 09:46 is between $I_{\text {limit }}$ and $1.1 I_{\text {limit }}$. Therefore, in this control period, we reconfigure the network only when $\alpha=0$; for other cases, curtailment is performed to resolve the overcurrent. 


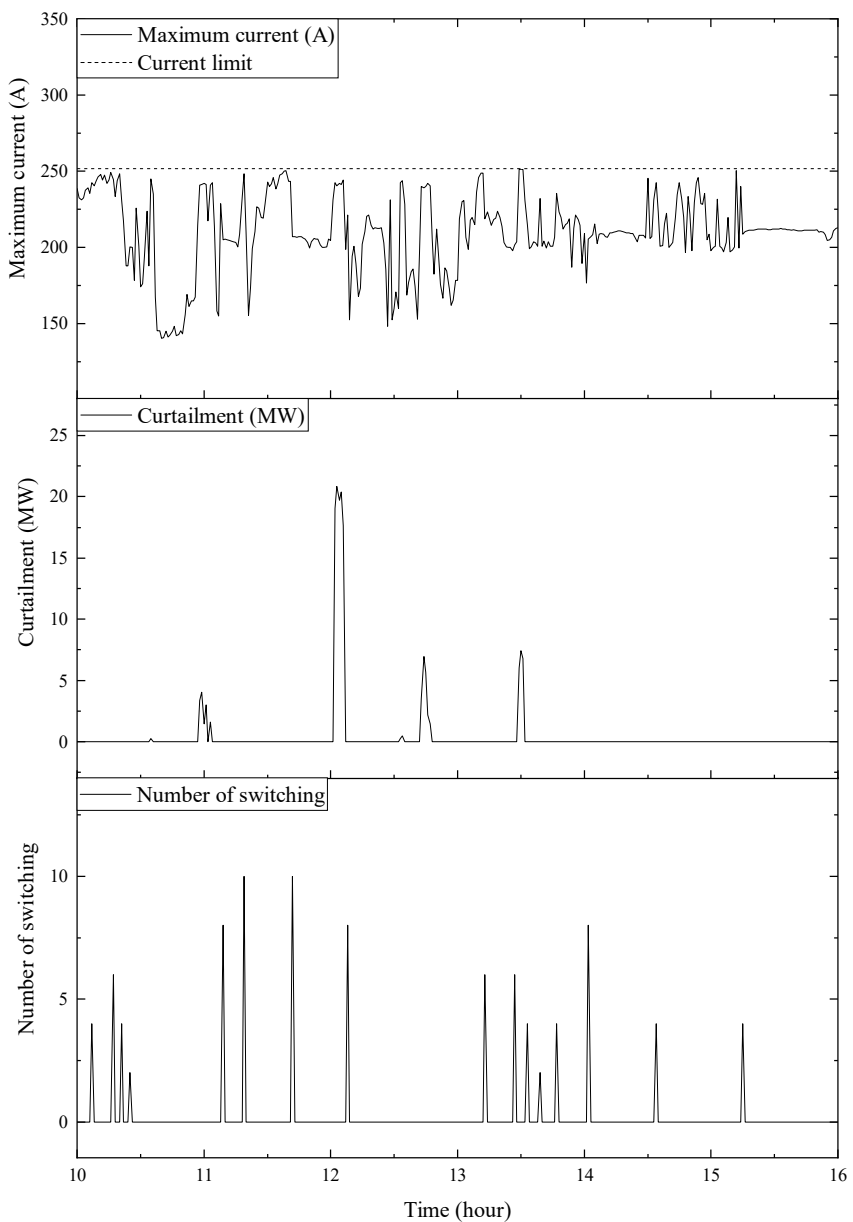

(a)

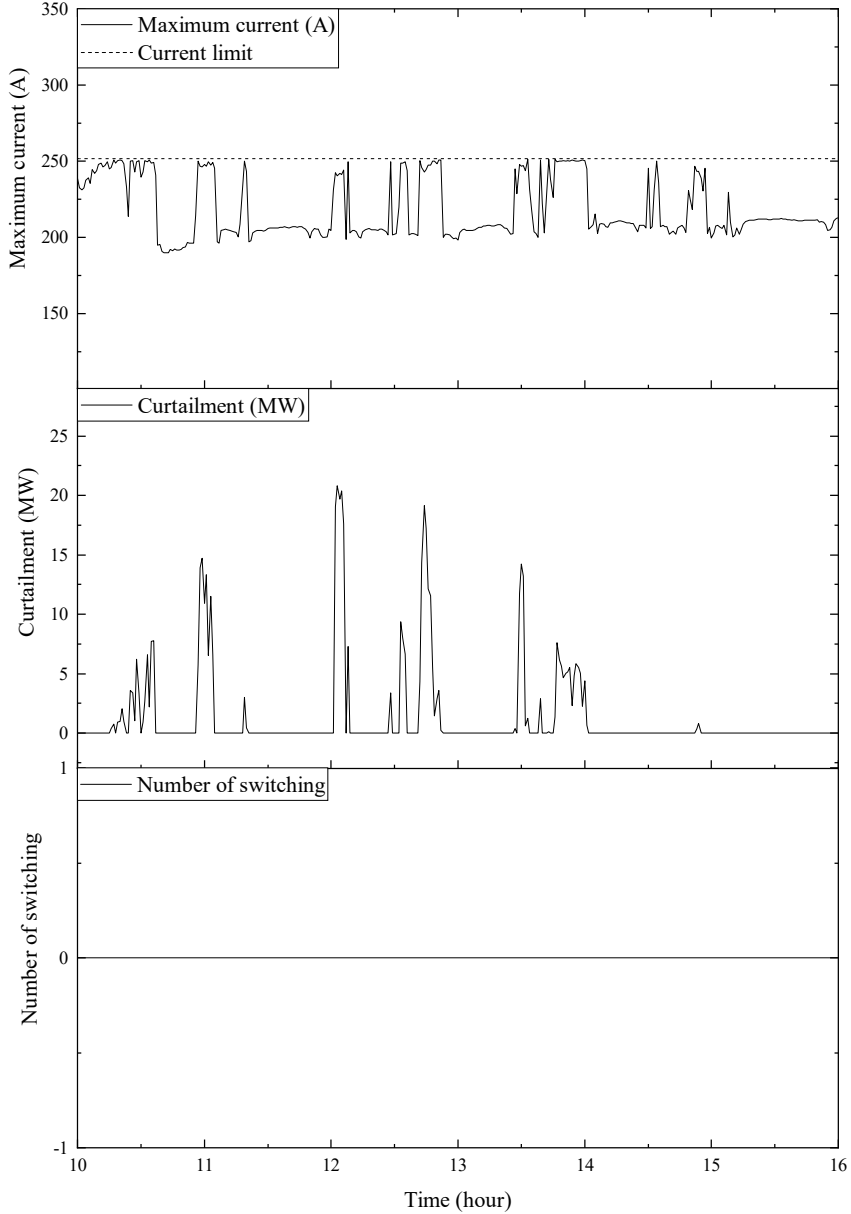

(b)

Figure 16. Curtailment and the number of switching operations: (a) network reconfiguration applied first; (b) with curtailment only.

At 13:01, the maximum current was predicted to be between $1.1 I_{\text {limit }}$ and $1.2 I_{\text {limit }}$; hence, in this case, the network should be reconfigured when $\alpha=0$ and $\alpha=0.1$. The overcurrent expected at 14:46 occurs because of the decrease in the PV output arising from the modified system topology, which should be resolved by network reconfiguration regardless of $\alpha$. Moreover, PV curtailment is not required in this case. On this day, the magnitude of the overcurrent was not large; therefore, the network was not reconfigured in the case of $\alpha=0.2$ and $\alpha=0.3$. Figure $17 \mathrm{~b}$ shows the amount of hourly curtailed power for each case. Between 09:00 and 13:00, the curtailment was the lowest when $\alpha=0$ because the network was reconfigured. However, the curtailment was not high in the other three cases. Between 13:00 and 14:00, the curtailment difference between the case with network reconfiguration $(\alpha=0,0.1)$ and the case without network reconfiguration $(\alpha=0.2,0.3)$ was large. Figure $17 \mathrm{c}, \mathrm{d}$ show the simulation results using the data for the 33rd day. For the overcurrent expected at 10:16, the network was reconfigured only when $\alpha=0$, and the system topology did not change in the other three cases. Accordingly, the figure shows that the curtailment at $\alpha=0$ between 10:00 and 13:00 is lower than that for the other three cases. As the overcurrent at 13:46 was expected to be higher than $1.2 I_{\text {limit }}$, the network was reconfigured in three cases: $\alpha=0,0.1$, and 0.2 . For $\alpha=0.3$ without reconfiguration, higher curtailment occurred than in the other three cases. The overcurrent expected at 15:16 was caused by the load due to the decrease in the PV output, as in the previous case, and network reconfiguration was required for all three cases $(\alpha=0,0.1$, and 0.2$)$. The simulation 
results of the two specific days confirm that the number of network reconfigurations (switch controls) decreases with an increase in $\alpha$, but a higher percentage of PV curtailment occurs to resolve the overcurrent.

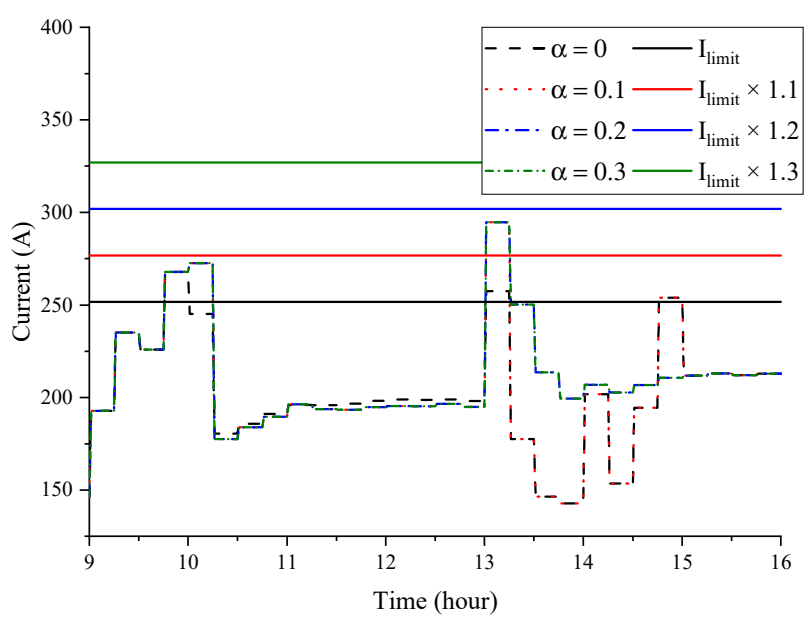

(a)

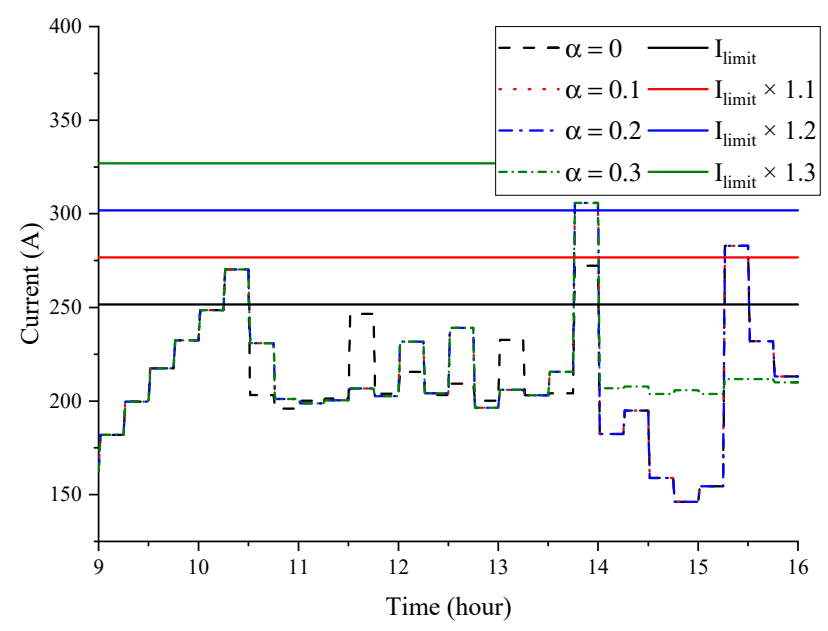

(c)

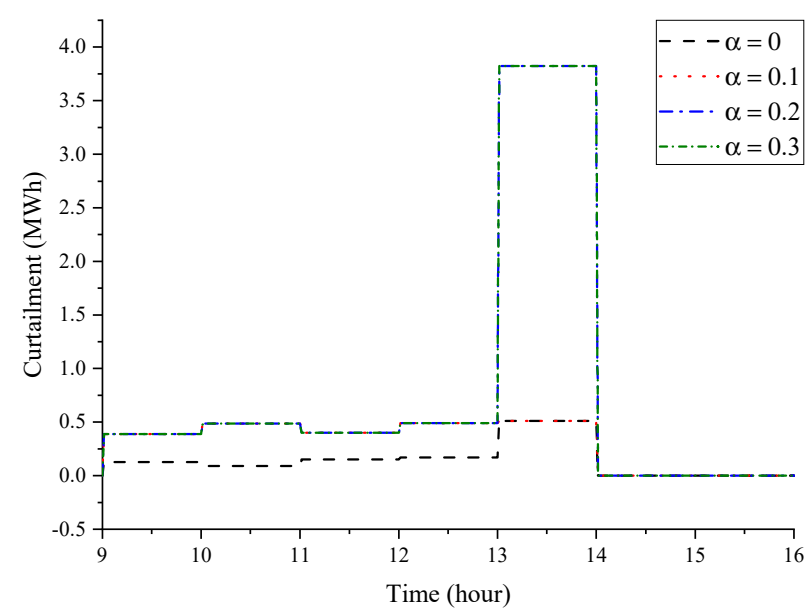

(b)

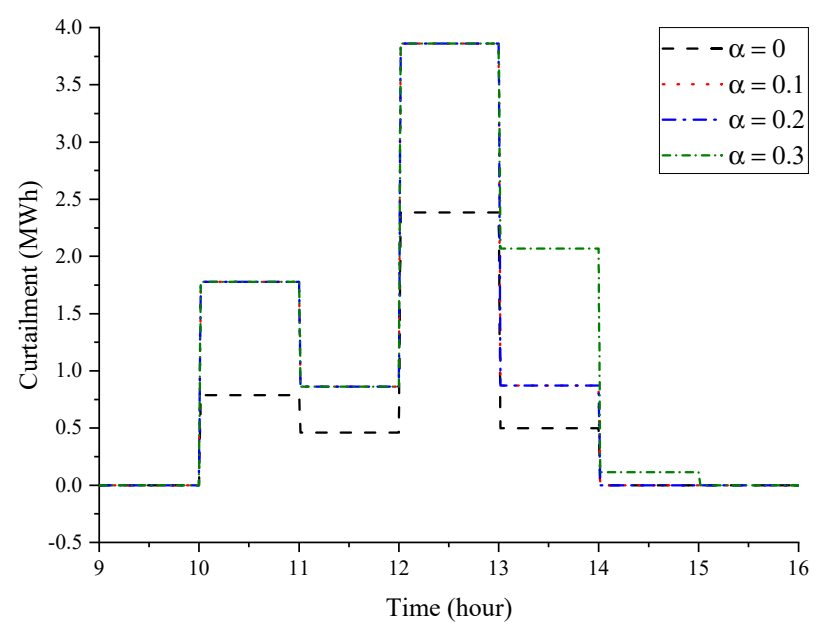

(d)

Figure 17. Maximum current and curtailment with respect to $\alpha$ on Days 4 and 33: (a) maximum current before control on Day 4; (b) curtailment on Day 4; (c) maximum current before control on Day 33; (d) curtailment on Day 33.

Next, we analyzed the effect of the control period. Our simulation with $\alpha=0$ used the data for the 33rd day. The results are shown in Figure 18. Specifically, Figure 18a shows the magnitude of the maximum section current of the system analyzed using the predicted data before deriving the control solution, when $\Delta T$ was set to $5,15,30$, and $60 \mathrm{~min}$. For control with $\Delta T=5 \mathrm{~min}$, the network was reconfigured nine times at 10:11, 10:26, 10:31, 12:01, 13:11, 13:26, 13:31, 13:46, and 15:16, respectively. For control with $\Delta T=15 \mathrm{~min}$, the network was reconfigured three times, and for $\Delta T=30 \mathrm{~min}$, two network reconfigurations were performed. For control with a $60 \mathrm{~min}$ period, no network reconfiguration was required. These results show that the number of reconfigurations decreases with an increased control period. Figure 18b shows the curtailed power for each case. According to our results, the curtailment increases with an increased control period. 


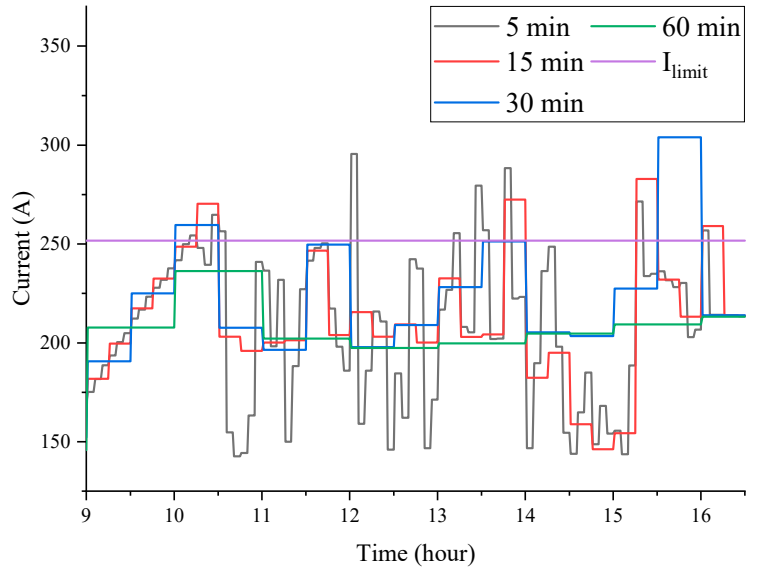

(a)

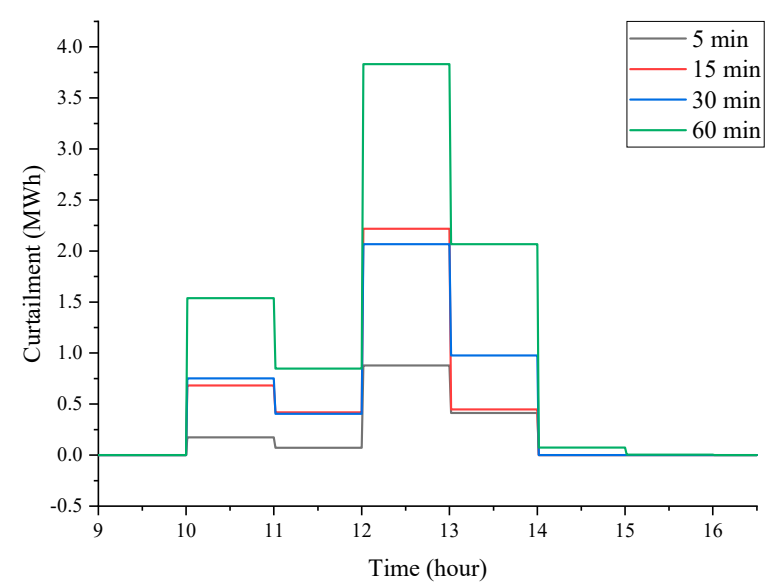

(b)

Figure 18. Maximum current and curtailment with respect to the control period on Day 33: (a) maximum current before control; (b) curtailment.

The previous simulations examined the results for specific days. To examine the effects of the control period and $\alpha$ value, our simulation covered 38 days, using five control periods $(1,5,15,30$, and $60 \mathrm{~min})$ and $\alpha$ values $(0,0.1,0.2,0.3$, and infinity (without reconfiguration)). Figure 19a shows the number of switching operations according to the network reconfiguration in each case. The number of switching operations was maximal when $\Delta T=1 \mathrm{~min}$ and $\alpha=0$, and it decreased with increasing the control period and $\alpha$. Figure 19b shows the PV curtailment in each case. The highest curtailment can be observed for the case without reconfiguration ( $\alpha=$ infinity), and it decreases with decreasing control period and $\alpha$.

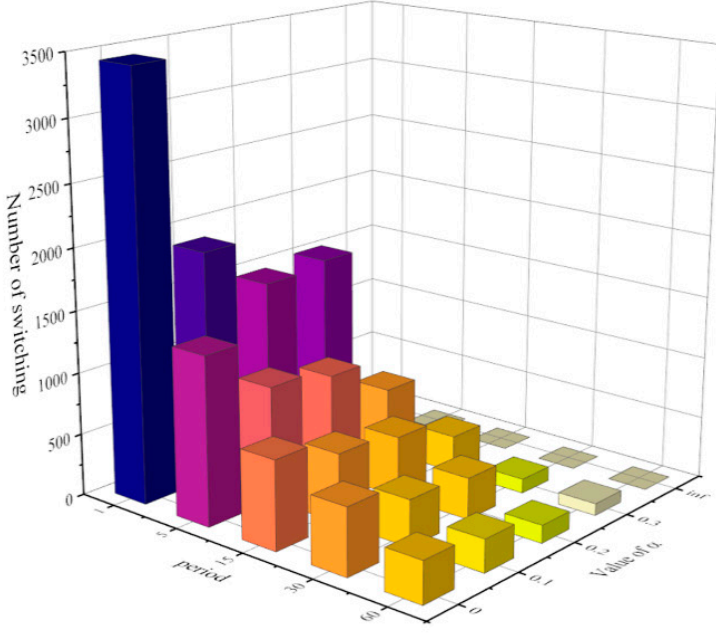

(a)
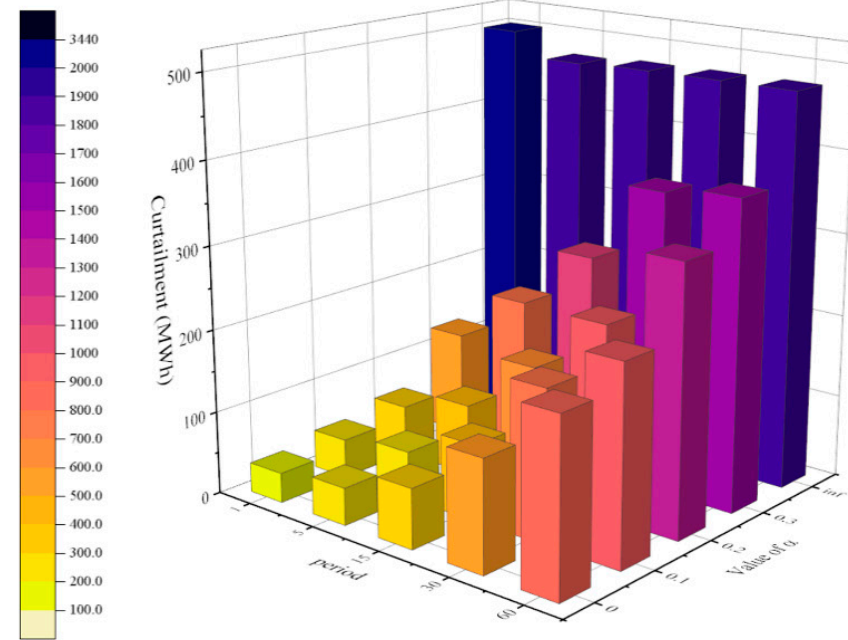

(b)

Figure 19. Number of switching operations and curtailment over 38 days with respect to $\alpha$ and the control period: (a) number of switching operations; (b) curtailment.

A network reconfiguration through switch control may lead to a power outage in the case of operation failure, and frequent opening/closing operations of the switch shorten the service life of the switch, posing a burden on the power system operator. However, the curtailment of DG may require economic compensation for DG owners depending on the market system, which can hinder the expansion of RES installations. Therefore, depending on the characteristics of the power system and the market system, the importance and priorities of the two different goals related to the number of switching operations and 
curtailment may vary. Therefore, to facilitate determining of an adequate control period and $\alpha$ value depending on the situation and objectives of system operations, we defined a performance index (P.I.) considering the respective weights of the two goals, as shown in Equation (10). After normalizing each of the two factors of P.I. with the average of all cases, a weighted sum was calculated.

$$
\text { P.I. }=\frac{N_{S W}(n, l)}{\operatorname{Avg}_{m \in \Omega_{\Delta T}, l \in \Omega_{\alpha}}\left(N_{S W}(n, l)\right)} \times \omega_{S W}+\frac{P_{c u r}(n, l)}{\operatorname{Avg}\left(P_{c u r}(n, l)\right)} \times \omega_{C u r}
$$

Here, $\Omega_{\Delta T}$ is the set of the control periods, $\Omega_{\alpha}$ is the set of $\alpha$ values, $N_{S W}(n, l)$ is the number of switching operations in this case, $P_{C u r}(n, l)$ is the curtailment in this case, and $\omega_{S W}$ and $\omega_{C u r}$ are the weights for the number of switching operations and curtailment, respectively.

Figure 20 compares P.I. according to $\alpha$ values and control periods in nine cases for different values of $\omega_{S W}$ and $\omega_{C u r}$. When $\omega_{S W} \geq 0.7$, the P.I. decreases with the increase in the control period and $\alpha$ value. Therefore, when assigning priority for reducing the number of switch control operations according to network reconfigurations, it is appropriate to perform curtailment only ( $\alpha=$ infinity) or to apply a control period of $60 \mathrm{~min}$.
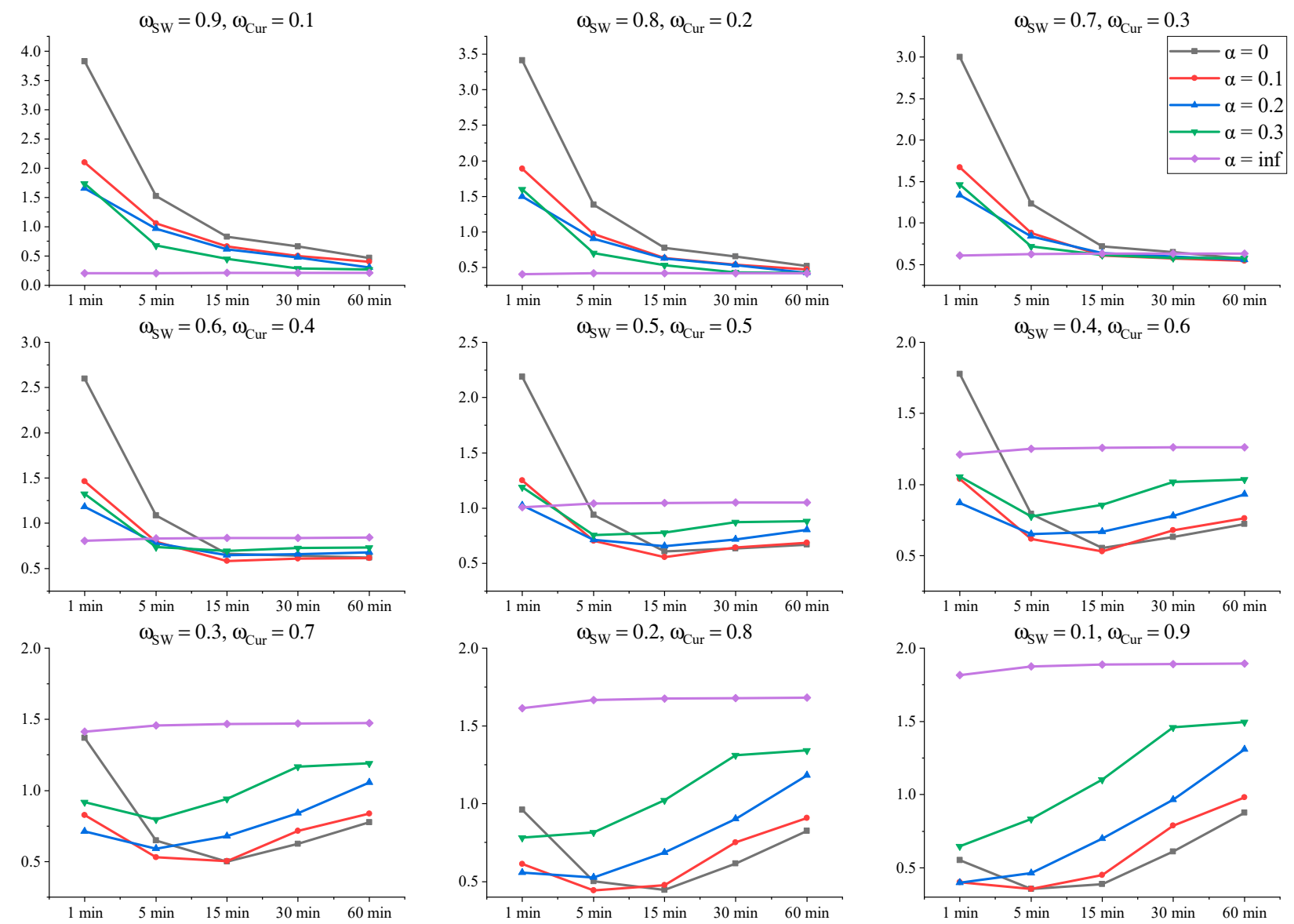

Figure 20. Comparison of P.I. for each case with respect to $\omega_{S W}$ and $\omega_{C u r}$.

When $\omega_{\text {Cur }} \geq 0.7$, the P.I. value decreases with an increase in $\alpha$ value and a decrease in the control period; however, this pattern is not as evident as that with a large $\omega_{S W}$. In situations when reducing the curtailment of DG is given priority, it is appropriate to select a control period of 5 or $15 \mathrm{~min}$ and an $\alpha$ value of 0 or 0.1 . When the importance of the two goals is similar, the P.I. value is the smallest when the control period is set to $15 \mathrm{~min}$ and $\alpha=0.1$. Currently, the period of the regular voltage management of KEPCO's distribution system and advanced metering infra structure (AMI) data measurement of the customers 
is also set to $15 \mathrm{~min}$; therefore, setting the control period at $15 \mathrm{~min}$ would not be difficult in terms of implementation and operation under the current infrastructure of the KEPCO system operation.

\subsection{Case 3: Simulation Results with the Increase in the HC}

Next, we analyzed the effect on the change in the number of switching control operations by reconfiguration and curtailment with the increase in the HC. Specifically, we increased the HC from $260 \%$ to $350 \%$ in steps of $10 \%$ in simulations. The effect on curtailment was evaluated by defining the incremental curtailment (I.C.) as the ratio of the increment of curtailment to the increment of the possible power output of PV with a $10 \%$ increase in the $\mathrm{HC}$, as shown in Equation (11).

$$
\text { I.C. }=\frac{\Delta P_{\text {cur }}}{\Delta P_{\text {avail }}} \times 100(\%)
$$

where $\Delta P_{\text {avail }}$ is the increment in the possible output (MWh) with a $10 \%$ increase in the $\mathrm{HC}$, and $\Delta P_{\text {cur }}$ is the increment of the curtailment (MWh) after applying the actual control. An I.C. of $50 \%$ indicates that, for a newly installed PV, half of the power output that can be generated will be curtailed because of the constraints in the system. Figure 21 shows the results for two cases: (1) $\Delta \mathrm{T}=15 \mathrm{~min}$ and $\alpha=0.1$ and (2) $\Delta \mathrm{T}=5 \mathrm{~min}$ and $\alpha=0.2$. Figure 21a shows the number of switching operations with the increase in the HC. If the control period and $\alpha$ value are fixed, the number of switching operations caused by reconfigurations does not change significantly with the increase in the HC. This is because, when the HC is above a certain level, even though the magnitude of possible overcurrent with PV increases, the frequency of overcurrent occurrences that require network reconfiguration no longer increases. Figure $21 \mathrm{~b}$ shows I.C. according to the HC. In both cases, if the HC is increased, I.C. also increases. When $\mathrm{HC}=350 \%$, for $\Delta \mathrm{T}=15 \mathrm{~min}$ and $\alpha=0.1,70 \%$ of the power output that could have been generated with additional installations of PV would be curtailed. For $\Delta \mathrm{T}=5 \mathrm{~min}$ and $\alpha=0.2,50 \%$ would be curtailed. Therefore, when considering the integration of additional DGs in a system with already integrated sources of renewable energy, the installation of new DGs should be determined based on the review of the economic feasibility, considering the new installation capacity, expected power output, and curtailments.

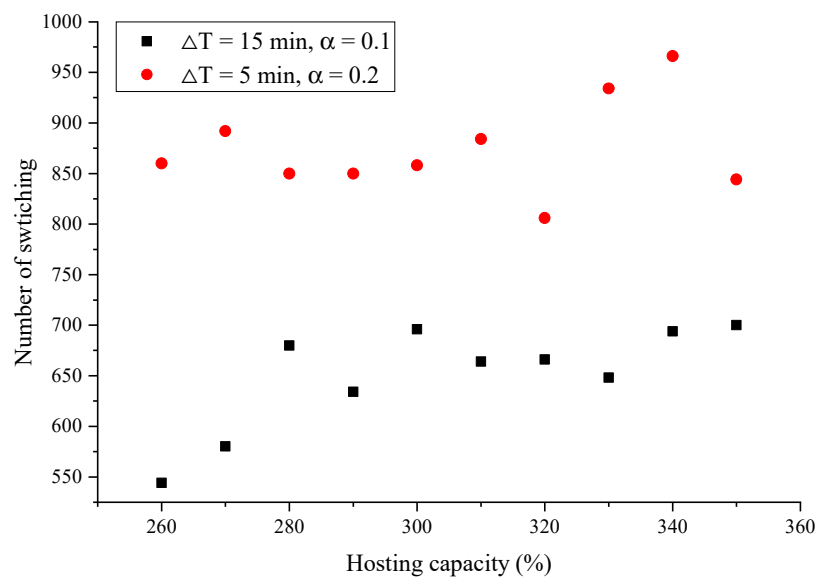

(a)

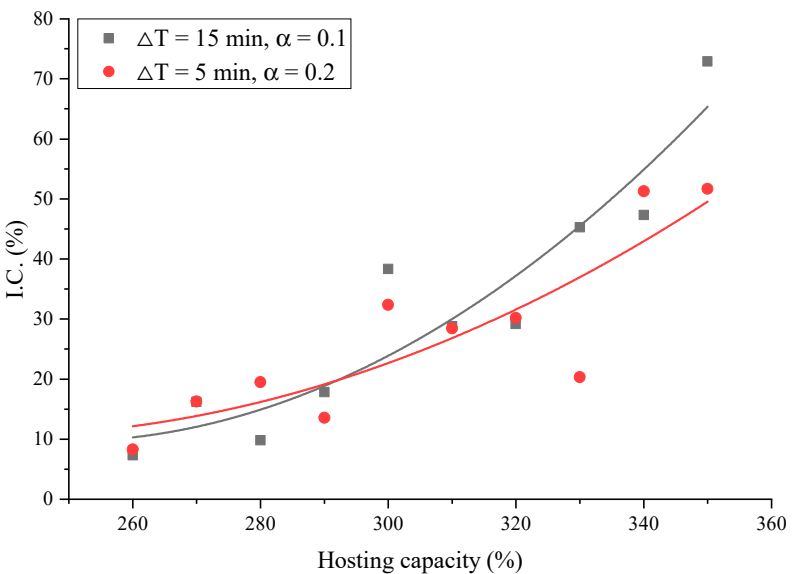

(b)

Figure 21. Comparison of the performance indices with respect to HC: (a) number of switching operations and (b) incremental curtailment. 


\section{Discussion}

The performance of the proposed short-term cooperative operational scheme was verified through three case studies in a test system similar to the actual distribution network. The simulation results can be summarized as follows.

(1) The P.I. value of the proposed heuristic network reconfiguration method was $32 \%$ greater than that of BPSO. However, it showed much improved performance compared to the conventional method, whose P.I. value was more than twice that of BPSO. Moreover, the average computation time of the proposed method was just $5 \mathrm{~s}$ while that of the BPSO was $71 \mathrm{~s}$.

(2) The performance of the proposed cooperative operational scheme was analyzed according to the change in control period and the control variable $\alpha$. The shorter the control period and the smaller the $\alpha$ value, the higher the number of switching operations. On the contrary, the amount of power curtailment increased when the control period was longer and the $\alpha$ value was larger. When the weighting factors of the number of switching operations and power curtailment were set similarly, the appropriate control period and $\alpha$ value were found to be $15 \mathrm{~min}$ and 0.1 , respectively.

(3) When HC increased above a certain value, the ratio of curtailment increased significantly even when the proposed method was applied, but the number of switching operations did not change significantly. Therefore, economic feasibility should be carefully reviewed before installing additional DGs in a system with high HC.

The excellence of the proposed method can be summarized as follows. First, the proposed heuristic network reconfiguration method can find near optimal solution in a short time, so it is suitable as a method to cope with real-time output fluctuations of DG. Second, the proposed method was able to effectively respond to the real-time output fluctuations of distributed power sources, thereby proving that it is possible to operate without violation even if the $\mathrm{HC}$ of the distribution network is greatly increased. These results showed that the installation of new infrastructure could be delayed even if the interconnection of DGs increases and, therefore, there is a great advantage when applied to the actual distribution system operation.

\section{Conclusions}

The real-time output fluctuation of RESs, which was difficult to respond with existing operation methods, becomes a greater risk to the operation of the distribution system as the HC increases. In this study, we proposed a short-term operation method to effectively resolve the congestion in a distribution system with high $\mathrm{HC}$, combining the methods of voltage control, network reconfiguration, and DG curtailment. In this scheme, we introduced novel methods of heuristic network reconfiguration and a method for determining the maximum output reference value of DGs. The proposed method can be implemented in a local controller that connects between the distribution management system (DMS) and the field devices and monitors and controls several feeders. The proposed method effectively resolved violations caused by output fluctuations of RESs while minimizing the amount of power curtailment and the number of switching operations through the appropriate combination of control period and reconfiguration execution conditions. Through the case studies, the proposed method was verified as an effective control method for increasing $\mathrm{HC}$ while deferring the installation of new infrastructure in the distribution system. Since the proposed network reconfiguration method can find a solution in $5 \mathrm{~s}$, even in a system with 192 nodes, it can be applied to local controllers where the solution needs to be derived quickly. Even if switch control fails, other solutions can be quickly derived, which reduce the burden on operators. As the interconnection of RES increases, more measurement devices are being installed. Moreover, recent DG inverters have various smart functions to comply with enhanced grid codes. Therefore, the proposed method can be applied to the current distribution system without large-scale investment, and is expected to contribute to increasing $\mathrm{HC}$. 
Author Contributions: C.-H.O. prepared the manuscript and implemented the theory and simulations. J.-H.C. and S.-Y.Y. analyzed the simulation results and commented on the manuscript. S.-J.A. supervised the study and discussed the results. All authors have read and agreed to the published version of the manuscript.

Funding: This work was supported by the National Research Foundation of Korea (NRF) grant funded by the Korea government (MSIT) (no. 2021R1F1A1047729). This research was supported by "Regional Innovation Strategy (RIS)" through the National Research Foundation of Korea (NRF) funded by the Ministry of Education (MOE) (2021RIS-002).

Institutional Review Board Statement: Not applicable.

Informed Consent Statement: Not applicable.

Data Availability Statement: Not applicable.

Conflicts of Interest: The authors declare no conflict of interest.

\section{Nomenclature}

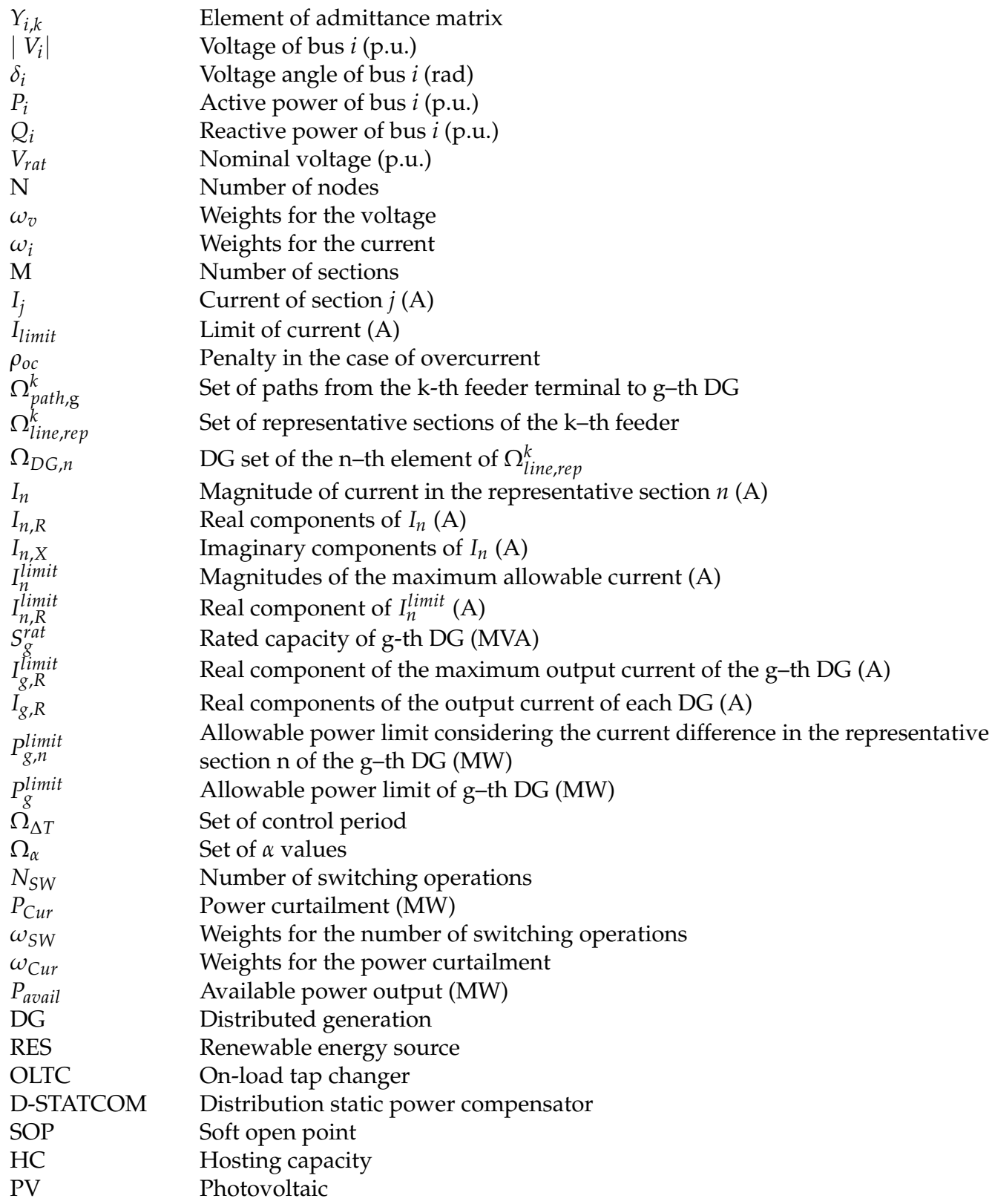




$\begin{array}{ll}\text { KEPCO } & \text { Korea electric power corporation } \\ \text { BPSO } & \text { Binary particle swarm optimization } \\ \text { P.I. } & \text { Performance index } \\ \text { I.C. } & \text { Incremental curtailment } \\ \text { AMI } & \text { Advanced metering infrastructure } \\ \text { DMS } & \text { Distribution management system }\end{array}$

\section{References}

1. Martins, V.F.; Borges, C.L.T. Active Distribution Network Integrated Planning Incorporating Distributed Generation and Load Response Uncertainties. IEEE Trans. Power Syst. 2011, 26, 2164-2172. [CrossRef]

2. Samuelsson, O.; Repo, S.; Jessler, R.; Aho, J.; Kärenlampi, M.; Malmquist, A. Active Distribution Network Demonstration Project ADINE. In Proceedings of the 2010 IEEE PES Innovative Smart Grid Technologies Conference Europe (ISGT Europe), Gothenburg, Sweden, 11-13 October 2010; pp. 1-8.

3. Lopes, J.A.P.; Hatziargyriou, N.; Mutale, J.; Djapic, P.; Jenkins, N. Integrating Distributed Generation into Electric Power Systems: A Review of Drivers, Challenges and Opportunities. Electr. Power Syst. Res. 2007, 77, 1189-1203. [CrossRef]

4. Silva, F.F.C.; Carvalho, P.M.S.; Ferreira, L.A.F.M. Improving PV Resilience by Dynamic Reconfiguration in Distribution Grids: Problem Complexity and Computation Requirements. Energies 2021, 14, 830. [CrossRef]

5. Jafari, A.; Ganjeh Ganjehlou, H.; Baghal Darbandi, F.; Mohammadi-Ivatloo, B.; Abapour, M. Dynamic and Multi-Objective Reconfiguration of Distribution Network Using a Novel Hybrid Algorithm with Parallel Processing Capability. Appl. Soft Comput. 2020, 90, 106146. [CrossRef]

6. Wang, J.; Wang, W.; Wang, H.; Zuo, H. Dynamic Reconfiguration of Multiobjective Distribution Networks Considering DG and EVs Based on a Novel LDBAS Algorithm. IEEE Access 2020, 8, 216873-216893. [CrossRef]

7. Wen, J.; Tan, Y.; Jiang, L.; Lei, K. Dynamic Reconfiguration of Distribution Networks Considering the Real-time Topology Variation. IET Gener. Transm. Distrib. 2018, 12, 1509-1517. [CrossRef]

8. Fu, Y.-Y.; Chiang, H.-D. Toward Optimal Multiperiod Network Reconfiguration for Increasing the Hosting Capacity of Distribution Networks. IEEE Trans. Power Deliv. 2018, 33, 2294-2304. [CrossRef]

9. Peng, C.; Xu, L.; Gong, X.; Sun, H.; Pan, L. Molecular Evolution Based Dynamic Reconfiguration of Distribution Networks With DGs Considering Three-Phase Balance and Switching Times. IEEE Trans. Ind. Inform. 2017, 15, 1866-1876. [CrossRef]

10. Ameli, A.; Ahmadifar, A.; Shariatkhah, M.-H.; Vakilian, M.; Haghifam, M.-R. A Dynamic Method for Feeder Reconfiguration and Capacitor Switching in Smart Distribution Systems. Int. J. Electr. Power 2017, 85, 200-211. [CrossRef]

11. Esmaeili, S.; Anvari-Moghaddam, A.; Jadid, S.; Guerrero, J.M. A Stochastic Model Predictive Control Approach for Joint Operational Scheduling and Hourly Reconfiguration of Distribution Systems. Energies 2018, 11, 1884. [CrossRef]

12. Pamshetti, V.B.; Singh, S.; Singh, S.P. Combined Impact of Network Reconfiguration and Volt-VAR Control Devices on Energy Savings in the Presence of Distributed Generation. IEEE Syst. J. 2018, 14, 995-1006. [CrossRef]

13. Murty, V.V.V.S.N.; Sharma, A.K. Optimal Coordinate Control of OLTC, DG, D-STATCOM, and Reconfiguration in Distribution System for Voltage Control and Loss Minimization. Int. Trans. Electr. Energy Syst. 2019, 29, e2752. [CrossRef]

14. Pilo, F.; Pisano, G.; Soma, G.G. Optimal Coordination of Energy Resources with a Two-Stage Online Active Management. IEEE Trans. Ind. Electron. 2011, 58, 4526-4537. [CrossRef]

15. Liu, Y.; Li, J.; Wu, L. Coordinated Optimal Network Reconfiguration and Voltage Regulator/DER Control for Unbalanced Distribution Systems. IEEE Trans. Smart Grid 2018, 10, 2912-2922. [CrossRef]

16. Diaaeldin, I.M.; Aleem, S.H.E.A.; El-Rafei, A.; Abdelaziz, A.Y.; Zobaa, A.F. Enhancement of Hosting Capacity with Soft Open Points and Distribution System Reconfiguration: Multi-Objective Bilevel Stochastic Optimization. Energies 2020, $13,5446$. [CrossRef]

17. Zhang, R.; Ma, H.; Hua, W.; Saha, T.K.; Zhou, X. Data-Driven Photovoltaic Generation Forecasting Based on a Bayesian Network With SpatialTemporal Correlation Analysis. IEEE Trans. Ind. Inform. 2019, 16, 1635-1644. [CrossRef]

18. Ramakrishna, R.; Scaglione, A.; Vittal, V.; DallAnese, E.; Bernstein, A. A Model for Joint Probabilistic Forecast of Solar Photovoltaic Power and Outdoor Temperature. IEEE Trans. Signal Process. 2018, 67, 6368-6383. [CrossRef]

19. Carriere, T.; Vernay, C.; Pitaval, S.; Kariniotakis, G. A Novel Approach for Seamless Probabilistic Photovoltaic Power Forecasting Covering Multiple Time Frames. IEEE Trans. Smart Grid 2020, 11, 2281-2292. [CrossRef]

20. Chai, S.; Xu, Z.; Jia, Y.; Wong, W.K. A Robust Spatiotemporal Forecasting Framework for Photovoltaic Generation. IEEE Trans. Smart Grid 2020, 11, 5370-5382. [CrossRef]

21. Matpower. Available online: https://matpower.org/ (accessed on 20 September 2021).

22. Go, S.-I.; Yun, S.-Y.; Ahn, S.-J.; Choi, J.-H. Voltage and Reactive Power Optimization Using a Simplified Linear Equations at Distribution Networks with DG. Energies 2020, 13, 3334. [CrossRef]

23. Gomes, F.V.; Carneiro, S.; Pereira, J.L.R.; Vinagre, M.P.; Garcia, P.A.N.; Araujo, L.R. A New Heuristic Reconfiguration Algorithm for Large Distribution Systems. IEEE Trans. Power Syst. 2005, 20, 1373-1378. [CrossRef]

24. Guedes, L.S.M.; Lisboa, A.C.; Vieira, D.A.G.; Saldanha, R.R. A Multiobjective Heuristic for Reconfiguration of the Electrical Radial Network. IEEE Trans. Power Deliv. 2013, 28,311-319. [CrossRef] 
25. Zin, A.A.M.; Ferdavani, A.K.; Khairuddin, A.B.; Naeini, M.M. Reconfiguration of Radial Electrical Distribution Network through Minimum-Current Circular-Updating-Mechanism Method. IEEE Trans. Power Syst. 2012, 27, 968-974.

26. Zin, A.A.M.; Ferdavani, A.K.; Khairuddin, A.B.; Naeini, M.M. Two Circular-Updating Hybrid Heuristic Methods for MinimumLoss Reconfiguration of Electrical Distribution Network. IEEE Trans. Power Syst. 2012, 28, 1318-1323.

27. Ahmed, A.; Ran, L.; Moon, S.; Park, J.-H. A Fast PV Power Tracking Control Algorithm with Reduced Power Mode. IEEE Trans. Energy Conver. 2013, 28, 565-575. [CrossRef]

28. Yang, Y.; Wang, H.; Blaabjerg, F.; Kerekes, T. A Hybrid Power Control Concept for PV Inverters With Reduced Thermal Loading. IEEE Trans. Power Electr. 2014, 29, 6271-6275. [CrossRef]

29. Choi, J.-H.; Park, D.-H. Mid-to-Long Term Operation Plan of Distribution Control Center According to Expansion of Distribution System Intelligent Equipment (Final Report); KEPCO: Naju, Korea, 2017; pp. 14-38.

30. Nguyen, D. Network Reconfiguration by BPSO Method. MATLAB Central File Exchange. 2021. Available online: https://www. mathworks.com/matlabcentral/fileexchange/45946-network-reconfiguration-by-bpso-method (accessed on 19 July 2021).

31. de Andrade, L.C.M.; Silva, N. da Efficient Neurofuzzy Model to Very Short-Term Load Forecasting. IEEE Latin Am. Trans. 2016, 14, 721-728.

32. Ju, Y.; Li, J.; Sun, G. Ultra-Short-Term Photovoltaic Power Prediction Based on Self-Attention Mechanism and Multi-Task Learning. IEEE Access 2020, 8, 44821-44829. [CrossRef] 